\title{
Naamines and Naamidines as Novel Agents against a Plant Virus and Phytopathogenic Fungi
}

\author{
Pengbin Guo ${ }^{1}$, Gang $\mathrm{Li}^{1}{ }^{1}$, Yuxiu Liu ${ }^{1}$, Aidang Lu ${ }^{1}$, Ziwen Wang ${ }^{1,2,3,4, * \text { (D) } \text { and }}$ \\ Qingmin Wang ${ }^{1,3, *}$ \\ 1 State Key Laboratory of Elemento-Organic Chemistry, Research Institute of Elemento-Organic Chemistry, \\ College of Chemistry, Nankai University, Tianjin 300071, China; 13212007181@163.com (P.G.); \\ 2120150654@mail.nankai.edu.cn (G.L.); liuyuxiu@nankai.edu.cn (Y.L.); aidang_lu@163.com (A.L.) \\ 2 Tianjin Key Laboratory of Structure and Performance for Functional Molecules, College of Chemistry, \\ Tianjin Normal University, Tianjin 300387, China \\ 3 Collaborative Innovation Center of Chemical Science and Engineering (Tianjin), Tianjin 300071, China \\ 4 Key Laboratory of Inorganic-Organic Hybrid Functional Materials Chemistry (Tianjin Normal University), \\ Ministry of Education, Tianjin 300387, China \\ * Correspondence: hxxywzw@tinu.edu.cn (Z.W.); wangqm@nankai.edu.cn (Q.W.); \\ Tel.: +86-22-2376-6531 (Z.W.); +86-22-2350-3952 (Q.W.)
}

Received: 9 July 2018; Accepted: 31 August 2018; Published: 3 September 2018

\begin{abstract}
Naamines, naamidines and various derivatives of these marine natural products were synthesized and characterized by means of nuclear magnetic resonance (NMR) spectroscopy and mass spectrometry. The activities of these alkaloids against a plant virus and phytopathogenic fungi were evaluated for the first time. A benzyloxy naamine derivative 15d displayed excellent in vivo activity against tobacco mosaic virus at $500 \mu \mathrm{g} / \mathrm{mL}$ (inactivation activity, 46\%; curative activity, 49\%; and protective activity, 41\%); its activities were higher than the corresponding activities of the commercial plant virucide ribavirin (32\%, 35\%, and 34\%, respectively), making it a promising new lead compound for antiviral research. In vitro assays revealed that the test compounds exhibited very good antifungal activity against 14 kinds of phytopathogenic fungi. Again, the benzyloxy naamine derivative 15d exhibited broad-spectrum fungicidal activity, emerging as a new lead compound for fungicidal research. Additional in vivo assays indicated that many of the compounds displayed inhibitory effects $>30 \%$.
\end{abstract}

Keywords: marine natural products; naamines; naamidines; anti-tobacco mosaic virus (TMV) activity; fungicidal activity

\section{Introduction}

Although the population of the world has more than doubled since the 1960s, and global agricultural production has risen to a similar extent, productive arable acreage has increased by only $10 \%$, and this differential has contributed to the demand for increases in food production [1,2]. Plant diseases, including diseases caused by phytopathogenic fungi and viruses, can lead to severe yield losses in agricultural and horticultural crops. Tobacco mosaic virus (TMV), noted for the first time on tobacco, was the earliest plant virus to be discovered and is the most well studied. TMV can infect more than 400 plant species belonging to 36 families [3]. Ribavirin is a widely used antiviral agent against TMV, but its antiviral effect is less than $50 \%$ at $500 \mu \mathrm{g} / \mathrm{mL}$. In fact, there are no agents that can completely inhibit TMV once it has infected the plants. Therefore, the development of more active antiviral agents is urgently needed [4].

A number of marine natural products have been developed as pesticides and pharmaceuticals. For example, nereistoxin was the first marine natural product to find commercial use as a pesticide $[5,6]$, 
the marine-derived compound ziconotide has been approved in the United States for the treatment of pain, and trabectedin is a marine-derived anticancer drug approved for use in the European Union [7]. With the development of improved separation methods, the number of bioactive natural products isolated from marine organisms has been increasing steadily. For example, work on the sponge Leucetta chagosensis has led to the isolation of interesting 2-amino imidazole alkaloids such as naamines (Figure 1) [8-10], isonaamines [8,9], naamidines (Figure 1) [9,11,12], and isonaamidines [13], all of which have a central imidazole ring. These alkaloids exhibit interesting biological activities, including antimicrobial activity [8-10], nitric oxide synthase inhibition activity [12], and cytotoxicity [10]. Naamidine A exhibits antitumor activity derived from its ability to regulate the kinases extracellular regulated protein kinase 1 (ERK1) and ERK2, a pathway that is not targeted by any current anticancer drugs [14]. Because these marine alkaloids have been isolated in only small quantities, their activity has not been extensively researched, and there have been no reports on the use of these alkaloids to prevent plant diseases.

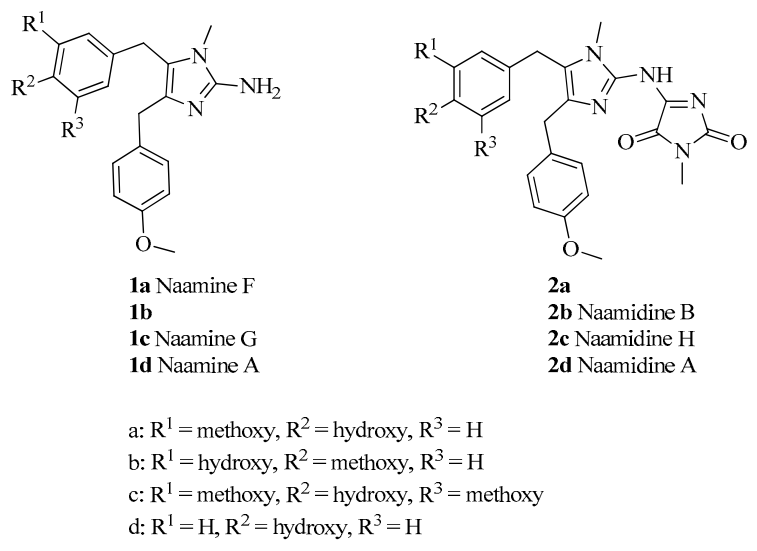

Figure 1. Structures of naamines $\mathbf{1 a}-\mathbf{d}$ and naamidines $\mathbf{2 a - d}$.

In work aimed at developing novel inhibitors of plant viruses from natural products, various natural products with novel structures, such as phenanthroindolizidines [15], harmine [16], topsentins [17], and matrine [18], have been found to have good antiviral activity. As a continuing work to find novel inhibitors of plant viruses from natural products, we synthesized various naamines, naamidines and derivatives, and systematically investigated their antiviral and antifungal activities.

\section{Results and Discussion}

\subsection{Chemistry}

Naamine A and naamidine A were first synthesized in 2000 [19], and naamines B [20], C and E-G [21] and naamidines $G$ and $H[22,23]$ were subsequently prepared by means of sequential metallization of imidazole or by alkyne amination. However, the reported methods are unsuitable for the preparation of analogues for studying structure-activity relationships (SARs) because they are low yielding, involve harsh reaction conditions, or require structurally complex starting materials. Therefore, new routes for the synthesis of naamines and naamidines are needed.

Herein, we describe the preparation of various analogues via the route shown in Figures 2 and 3. First, substituted benzaldehydes $\mathbf{3 a}-\mathbf{c}$ were first prepared. Then, the phenol moiety of $\mathbf{3}$ was protected with a benzyl group, and condensation reactions of the protected compounds with acetoacetic acid gave oxazoles 5 , which were hydrolyzed with aqueous $\mathrm{NaOH}$ and acidified with dilute aqueous $\mathrm{HCl}$ to give acids 6 . Hydrogenation over $\mathrm{Pd} / \mathrm{C}$ reduced the double bond and removed the benzyl protecting group to give phenylalanine $\mathbf{8 a}-\mathbf{c}$ after treatment with concentrated $\mathrm{HCl}$. Naamines $\mathbf{1 a}-\mathbf{d}$ and naamidines $\mathbf{2 a}-\mathbf{d}$ were then prepared from $\mathbf{8} \mathbf{a}-\mathbf{d}$ by means of a pathway involving cyanamide 
cyclization as the key step (Figure 3). Boc protection of the amino group and benzyl protection of the phenol group of 8 gave acids 10, which were methylated with iodomethane to obtain 11. Condensation of $\mathbf{1 1}$ with $\mathrm{N}, \mathrm{O}$-dimethylhydroxylamine hydrochloride gave Weinreb amides 12. Subsequent Grignard reaction and removal of the Boc protecting group gave aminoketones 14, which were cyclized with cyanamide to give key intermediates $\mathbf{1 5}$. Hydrogenation of $\mathbf{1 5}$ to remove the benzyl protecting group gave naamines 1 . Condensation of naamines 1 with 17 , which was prepared by the procedure depicted in Figure 3 afforded naamidines 2.

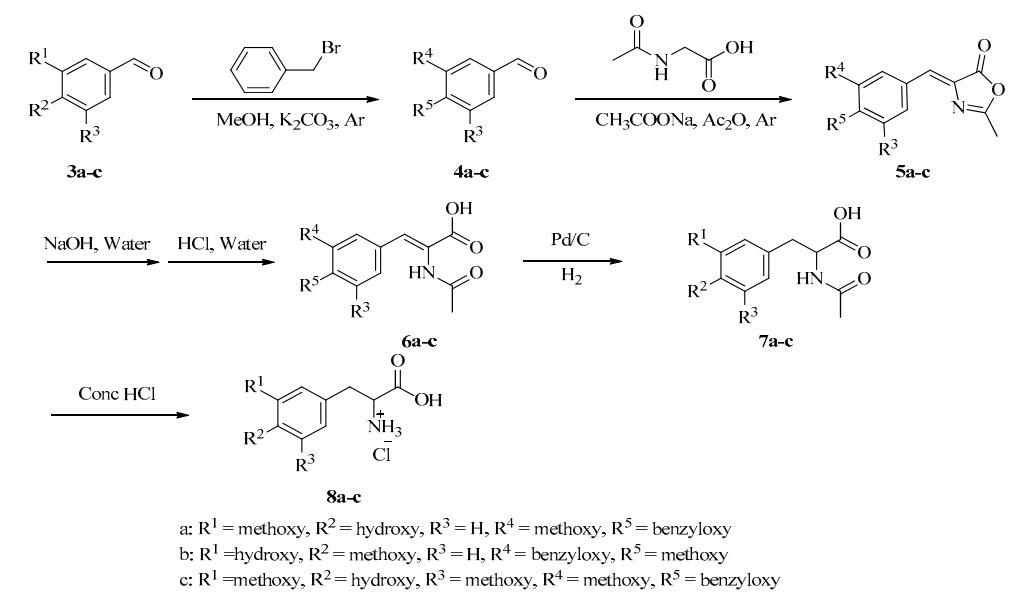

Figure 2. Synthesis of amino acids $8 \mathbf{a}-\mathbf{c}$.
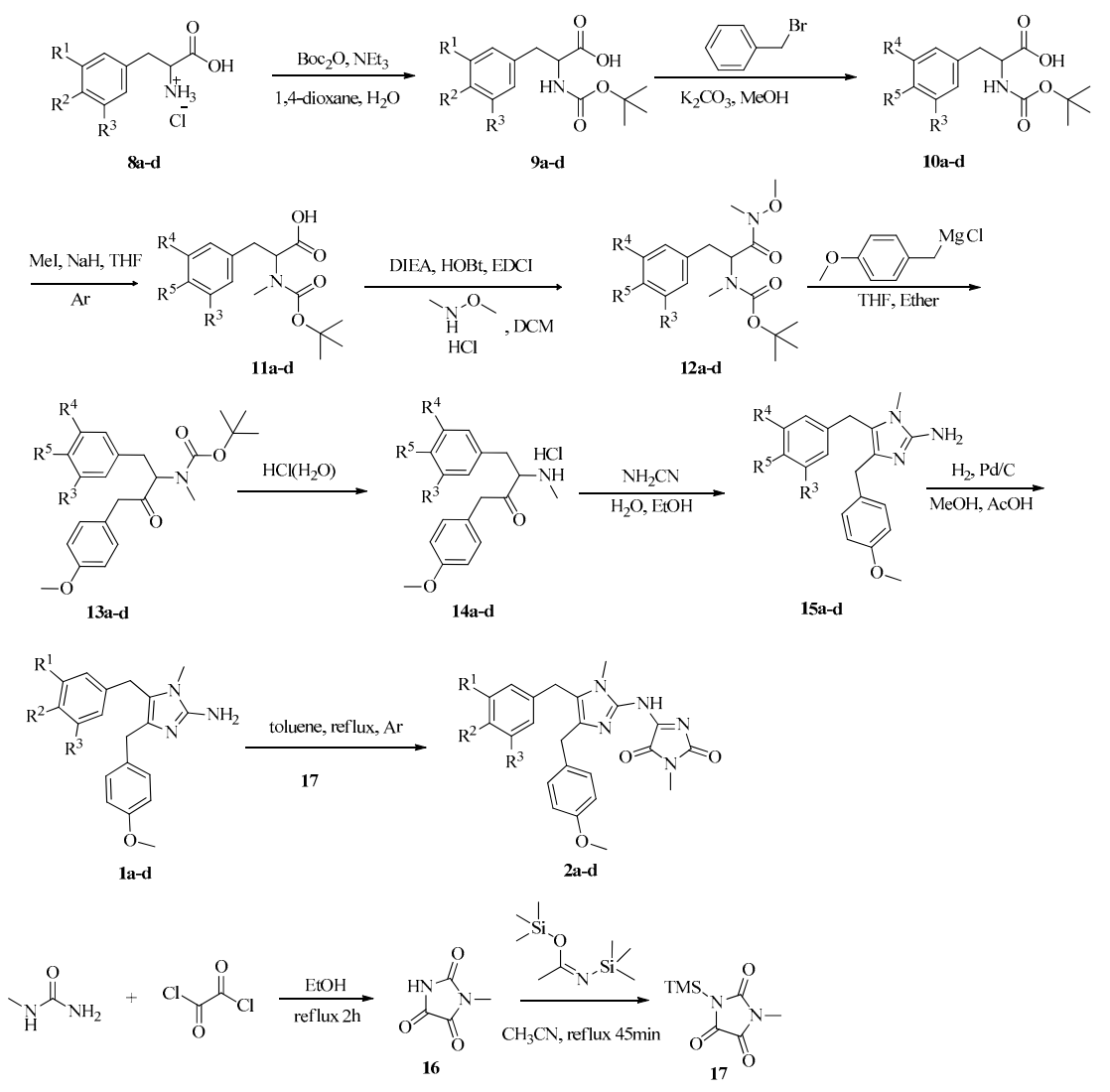

a: $\mathrm{R}^{1}=$ methoxy, $\mathrm{R}^{2}=$ hydroxy, $\mathrm{R}^{3}=\mathrm{H}, \mathrm{R}^{4}=$ methoxy, $\mathrm{R}^{5}=$ benzyloxy

b: $\mathrm{R}^{1}=$ hydroxy, $\mathrm{R}^{2}=$ methoxy, $\mathrm{R}^{3}=\mathrm{H}, \mathrm{R}^{4}=$ benzyloxy, $\mathrm{R}^{5}=$ methoxy

c: $\mathrm{R}^{1}=$ methoxy, $\mathrm{R}^{2}=$ hydroxy, $\mathrm{R}^{3}=$ methoxy, $\mathrm{R}^{4}=$ methoxy, $\mathrm{R}^{5}=$ benzyloxy

d: $\mathrm{R}^{1}=\mathrm{H}, \mathrm{R}^{2}=$ hydroxy, $\mathrm{R}^{3}=\mathrm{H}, \mathrm{R}^{4}=\mathrm{H}, \mathrm{R}^{5}=$ benzyloxy

Figure 3. Synthesis of naamines $\mathbf{1 a}-\mathbf{d}$ and naamidines $\mathbf{2 a}-\mathbf{d}$. 
To investigate SARs, we also designed and synthesized derivatives $1 \mathbf{e}-\mathbf{o}$ and $\mathbf{2 e}$. As depicted in Figure 4, acetylation of 2-aminoimidazole $\mathbf{1 5 d}$ with various acyl chlorides gave a mixture of $\mathbf{1 8}$ and $\mathbf{1 9}$, regardless of the temperature or the amount of acyl chloride. Fortunately, amides $\mathbf{1 8}$ could be converted to 19 by treatment with concentrated $\mathrm{HCl}$. Deprotection of 19 afforded 1e-i. Reductive amination of naamine $\mathbf{1 d}$ gave naamines $\mathbf{1} \mathbf{j}$ and $\mathbf{1 k}$ (Figure 5). As shown in Figure 6, we attempted to prepare dimethyl imidazole amine $\mathbf{2 l}$ by methylation of naamine $\mathbf{1 d}$, but we obtained only dimethyl ketone $\mathbf{1 l}$ because 21 was too sensitive to $\mathrm{H}_{2} \mathrm{O}$. To investigate the impact of salification and metal complexation, we also synthesized naamines $\mathbf{1 m - \mathbf { o }}$ (Figure 7) and naamidine-metal complex 2e (Figure 8).

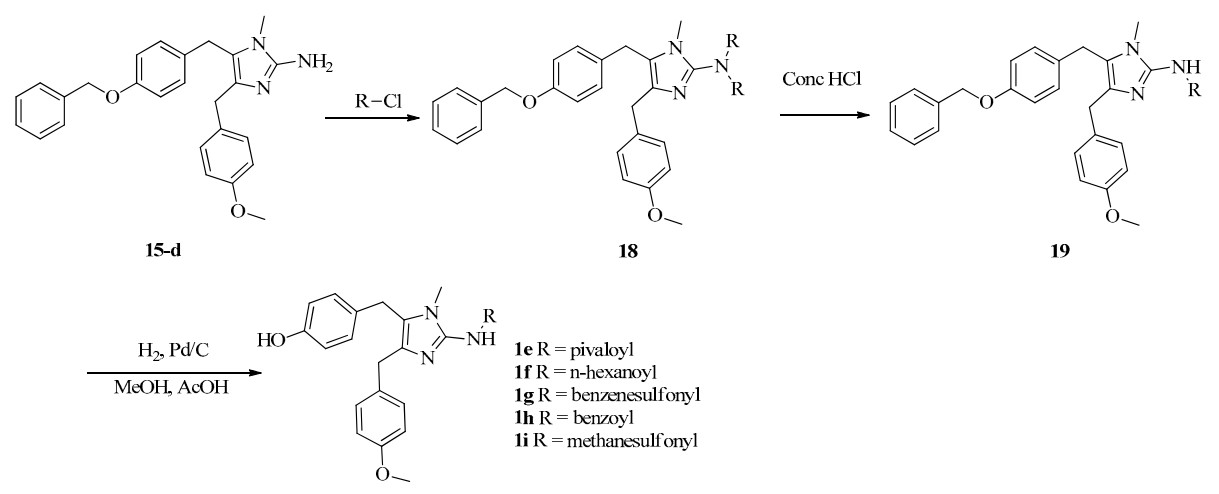

Figure 4. Synthesis of naamines 1e-i.

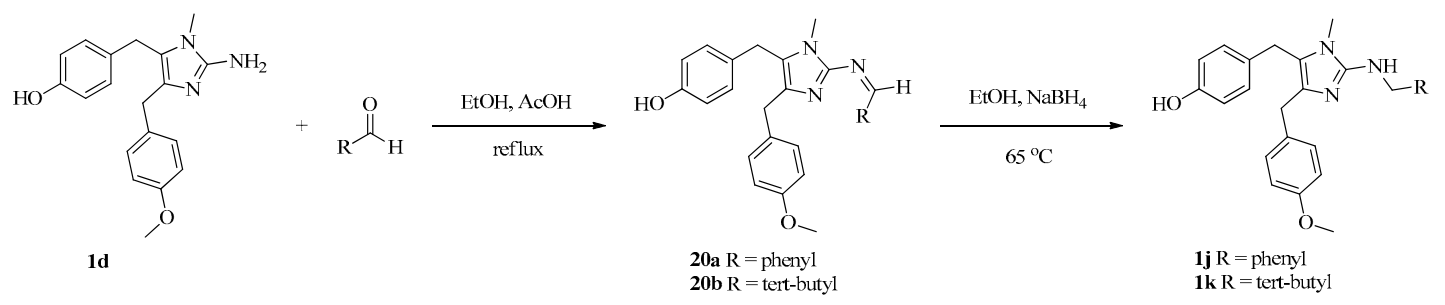

Figure 5. Synthesis of naamines $\mathbf{1 j}$ and $\mathbf{1 k}$.

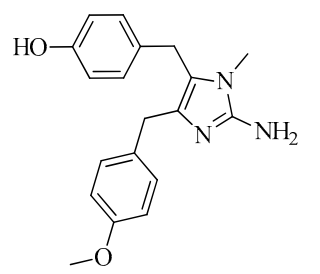

1d

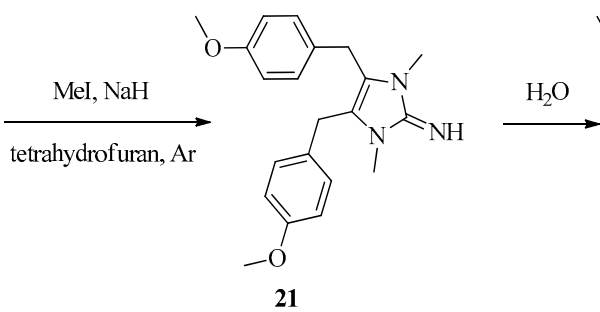

21

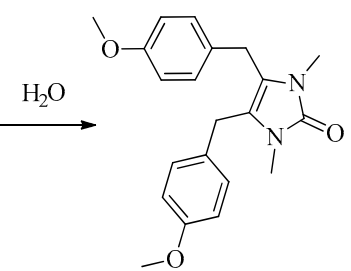

11

Figure 6. Synthesis of naamine $\mathbf{1 1 .}$<smiles></smiles>

Figure 7. Synthesis of naamines $\mathbf{1 m}-\mathbf{o}$. 


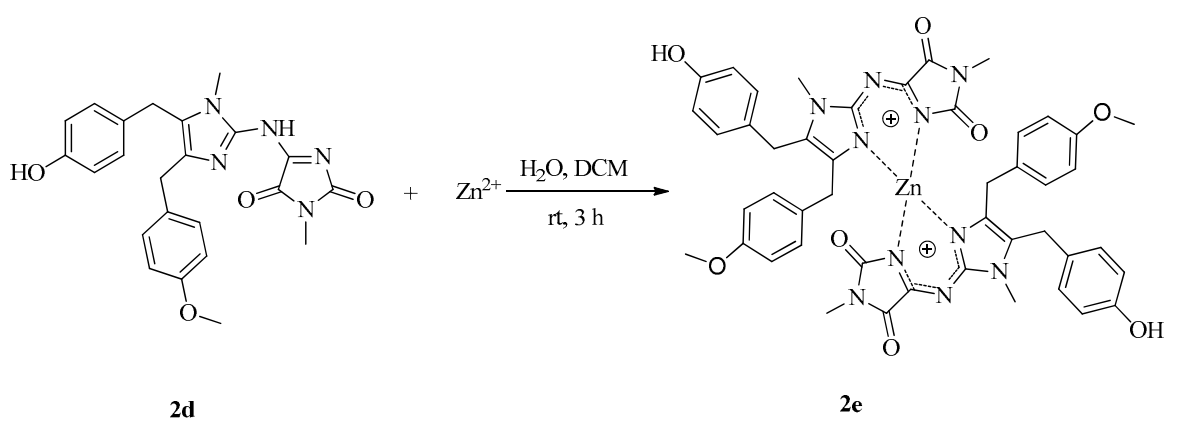

Figure 8. Synthesis of naamidine-metal complex $2 \mathbf{e}$.

\subsection{Phytotoxic Activity}

Compounds 1, 2 and 15 were found to show no phytotoxic activity at $500 \mu \mathrm{g} / \mathrm{mL}$.

\subsection{Antiviral Activity}

The anti-tobacco mosaic virus (TMV) activities of 1, 2 and 15 were compared with those of the commercial plant virucide ribavirin (positive control) and $0.1 \%$ Tween-80 solution (negative control) (Table 1).

Table 1. Activities of 1a-o, 2a-e and 15a-d against tobacco mosaic virus (TMV) at $500 \mu \mathrm{g} / \mathrm{mL}$.

\begin{tabular}{|c|c|c|c|c|}
\hline \multirow{2}{*}{ Compound } & \multirow{2}{*}{$\begin{array}{c}\text { In Vitro Inhibition } \\
\text { Rate }(\%)^{a}\end{array}$} & \multicolumn{3}{|c|}{ In Vivo } \\
\hline & & Inactivation Effect (\%) ${ }^{a}$ & Curative Effect (\%) ${ }^{a}$ & Protection Effect $(\%)^{a}$ \\
\hline $1 \mathrm{a}$ & $26 \pm 2$ & $32 \pm 2$ & $35 \pm 1$ & $28 \pm 2$ \\
\hline $1 b$ & $32 \pm 1$ & $31 \pm 1$ & $27 \pm 2$ & $35 \pm 1$ \\
\hline 1c & 0 & $7 \pm 2$ & 0 & 0 \\
\hline 1d & 0 & $14 \pm 2$ & 0 & $6 \pm 2$ \\
\hline 1e & $9 \pm 2$ & $22 \pm 3$ & $12 \pm 2$ & $16 \pm 2$ \\
\hline 1f & 0 & $14 \pm 2$ & 0 & $18 \pm 2$ \\
\hline $1 \mathrm{~g}$ & $18 \pm 1$ & $34 \pm 2$ & $29 \pm 1$ & $37 \pm 2$ \\
\hline $1 \mathrm{~h}$ & 0 & $18 \pm 1$ & $10 \pm 2$ & 0 \\
\hline $1 \mathbf{i}$ & $17 \pm 2$ & $15 \pm 2$ & 0 & $12 \pm 2$ \\
\hline $1 \mathrm{j}$ & $22 \pm 1$ & $26 \pm 2$ & $29 \pm 3$ & $17 \pm 2$ \\
\hline $1 \mathrm{k}$ & $10 \pm 2$ & $17 \pm 2$ & $22 \pm 1$ & $12 \pm 2$ \\
\hline 11 & 0 & 0 & $10 \pm 2$ & 0 \\
\hline $1 \mathrm{~m}$ & $12 \pm 1$ & $32 \pm 2$ & $24 \pm 1$ & $22 \pm 2$ \\
\hline 1n & $18 \pm 3$ & $23 \pm 2$ & $12 \pm 1$ & $20 \pm 2$ \\
\hline 10 & $16 \pm 2$ & $14 \pm 2$ & $9 \pm 2$ & 0 \\
\hline $2 \mathbf{a}$ & 0 & $31 \pm 2$ & $20 \pm 1$ & $22 \pm 2$ \\
\hline $2 b$ & $21 \pm 1$ & 0 & $12 \pm 2$ & $16 \pm 2$ \\
\hline $2 c$ & 0 & $8 \pm 2$ & $10 \pm 1$ & 0 \\
\hline $2 d$ & $12 \pm 2$ & 0 & 0 & $10 \pm 2$ \\
\hline $2 e$ & $25 \pm 2$ & $34 \pm 2$ & $37 \pm 1$ & $29 \pm 2$ \\
\hline $15 a$ & $23 \pm 1$ & $35 \pm 2$ & $29 \pm 2$ & $32 \pm 2$ \\
\hline $15 b$ & $36 \pm 2$ & $30 \pm 2$ & $33 \pm 2$ & $27 \pm 2$ \\
\hline $15 c$ & $12 \pm 2$ & $21 \pm 2$ & $16 \pm 1$ & $22 \pm 2$ \\
\hline $15 d$ & $43 \pm 2$ & $46 \pm 2$ & $49 \pm 2$ & $41 \pm 2$ \\
\hline Tween-80 & 0 & 0 & 0 & 0 \\
\hline Ribavirin & $39 \pm 1$ & $32 \pm 1$ & $35 \pm 2$ & $34 \pm 1$ \\
\hline
\end{tabular}

${ }^{a}$ Average of three replicates; all results are expressed as means $\pm \mathrm{SD}$.

\subsubsection{In Vitro Anti-tobacco Mosaic Virus (TMV) Activity}

Most of the synthesized compounds exhibited moderate antiviral activity in vitro, and $\mathbf{1 5 d}$, which showed higher inhibitory effect than ribavirin, emerged as a new lead compound for antiviral research. Among the naamine alkaloids $\mathbf{1 a}-\mathbf{d}$, compounds $\mathbf{1 a}$ and $\mathbf{1 b}$ showed good activity, whereas 
1c and $1 \mathrm{~d}$ displayed no inhibitory effect, these results indicated that the positions and numbers of methoxy and hydroxyl groups on aromatic ring are critical to maintaining biological activity and this region is very sensitive to electronegativity. Naamine derivatives $\mathbf{1 e - \mathbf { o }}$ displayed relatively lower antiviral activity, which shows that derivatization of the amino group and salification decreased active. Naamidine alkaloids $\mathbf{2 a}$ and $\mathbf{2 c}$ showed no activity, whereas $\mathbf{2 b}$ and $\mathbf{2 d}$ were moderately active. The main difference between $\mathbf{1 a}-\mathbf{d}$ and $\mathbf{2 a}-\mathbf{d}$ lies in the introduction of the imidazolone ring, which leads to obvious changes of activity (inhibitory effect: $\mathbf{2 a}<\mathbf{1 a}, \mathbf{2} \mathbf{b}<\mathbf{1 b}$ ). Zinc complex $\mathbf{2 e}$ displayed moderate activity. Interestingly, the introduction of a benzyloxy group on the aromatic ring was favorable for activity (inhibitory effect: $1 \mathrm{a} \approx \mathbf{1 5 a}, \mathbf{1 b}<\mathbf{1 5 b}, \mathbf{1 c}<\mathbf{1 5 c}, \mathbf{1 d}<\mathbf{1 5 d}$ ). However, further introduction of a methoxy group decreased activity (inhibitory effect: $15 \mathbf{c}<\mathbf{1 5 a}<\mathbf{1 5 d}$ ). The main difference between $\mathbf{1 5 a}$ and $\mathbf{1 5 b}$ lies in the changes in the position of benzoxy group and methoxyl, which leads to obvious changes in activity (inhibitory effect: $15 a<15 b$ ).

\subsubsection{In Vivo Anti-TMV Activity}

As shown in Table 1, most of the compounds showed in vivo anti-TMV activity that was similar to or higher than that of ribavirin. As in the in vitro assay, compound $\mathbf{1 5 d}$ showed the best activity in vivo at $500 \mu \mathrm{g} / \mathrm{mL}$ (inactivation activity: $46 \%$; curative activity: $49 \%$; and protection activity: $41 \%$ ), which is significantly higher than that of ribavirin (32\%, 35\%, and $34 \%$, respectively). The in vivo activities of compounds $\mathbf{1 g}, \mathbf{1 m}, \mathbf{2 a}, \mathbf{2 e}$ and $\mathbf{1 5 a}$ are significantly higher than those in vitro, which reveals that these compounds may display certain inducible activity.

Unlike in the in vitro assay, in the in vivo assay, $1 \mathrm{~g}, \mathbf{2 e}$ and $\mathbf{1 5 b}$ displayed activities that were similar to that of ribavirin. The other SARs in vivo are similar to those of in vitro.

\subsection{Fungicidal Activity}

Compounds 1, 2 and 15 were also evaluated for their in vitro and in vivo fungicidal activities, which were compared with those of the commercial fungicides chlorothalonil, carbendazim and azoxystrobin (positive controls) and sterile water (negative control).

\subsubsection{In Vitro Fungicidal Activity}

All the tested compounds displayed very good in vitro activity against 14 kinds of plant fungi at $50 \mu \mathrm{g} / \mathrm{mL}$ (Table 2), and most of the compounds displayed high bioselectivity. The fungicidal activity of naamidine $\mathrm{H}(\mathbf{2} \mathbf{c})$ against Cercospora arachidicola Hori was higher than that of carbendazim. Compounds 1b, 1k, 15a, 15c and 15d exhibited higher fungicidal activity against Physalospora piricola than did carbendazim. The fungicidal activities of naamine A (1d), derivatives $\mathbf{1 j}, \mathbf{1 m}$ and naamidine $\mathrm{H}(\mathbf{2 c})$ against Rhizoctonia cerealis were higher than that of carbendazim and similar to that of chlorothalonil. Against Phytophthora capsici, compounds $\mathbf{1 5 a} \mathbf{a} \mathbf{d}$ were more active than naamines $\mathbf{1}$ and naamidines 2, which indicated that the hydroxyl on the aromatic ring is bad for antifungal activity. Derivative 15d, with its broad-spectrum fungicidal activity, emerged as a new lead compound for fungicidal research. Among the naamine alkaloids $\mathbf{1 a}-\mathbf{d}, \mathbf{1} \mathbf{b}$ showed good activity against Physalospora piricola, 1c showed good activity against Alternaria solani, $\mathbf{1 d}$ showed good activity against Rhizoctonia cerealis and Fusarium graminearum, which indicated that different fungus displays different selectivity for compounds. Similar activity rules also can be found from $\mathbf{2 a}-\mathbf{d}$. The replacement of the amino group at 2-position of imidazole ring with oxygen and salification with trifluoroacetic acid are favorable for antifungal activity against Sclerotinia sclerotiorum and Botrytis cinerea. 
Table 2. In vitro activities of $1 \mathbf{a}-\mathbf{o}, \mathbf{2 a}-\mathbf{e}$ and $15 \mathbf{a}-\mathbf{d}$ against 14 kinds of fungi.

\begin{tabular}{|c|c|c|c|c|c|c|c|c|c|c|c|c|c|c|}
\hline \multirow{2}{*}{ Compound } & \multicolumn{14}{|c|}{ Fungicidal Activity ${ }^{a}(\%) / 50 \mu \mathrm{g} / \mathrm{mL}$} \\
\hline & F.C ${ }^{c}$ & C.H & P.P & R.C & B.M & W.A & F.M & A.S & F.G & P.I & P.C & S.S & R.S & B.C \\
\hline $1 \mathbf{a}$ & $12 \pm 1$ & $30 \pm 2$ & $11 \pm 1$ & $21 \pm 2$ & $20 \pm 2$ & $28 \pm 1$ & $22 \pm 2$ & $25 \pm 3$ & $28 \pm 2$ & $17 \pm 2$ & $9 \pm 1$ & $38 \pm 2$ & $40 \pm 1$ & $38 \pm 2$ \\
\hline $1 b$ & \pm 2 & $30 \pm 3$ & $67 \pm 2$ & $21 \pm 1$ & $28 \pm 2$ & $28 \pm 1$ & $19 \pm 2$ & $38 \pm 2$ & $36 \pm 1$ & $25 \pm 2$ & $17 \pm 2$ & $30 \pm 3$ & $47 \pm 2$ & $24 \pm 1$ \\
\hline 1c & $20 \pm 1$ & $27 \pm 2$ & 0 & $18 \pm 2$ & $23 \pm 1$ & $33 \pm 2$ & $26 \pm 1$ & $50 \pm 2$ & $24 \pm 2$ & $17 \pm 1$ & $9 \pm 2$ & $27 \pm 1$ & $20 \pm 2$ & $24 \pm 1$ \\
\hline $1 d$ & $32 \pm 2$ & $47 \pm 1$ & $44 \pm 2$ & $70 \pm 1$ & $35 \pm 2$ & $47 \pm 3$ & $37 \pm 2$ & $44 \pm 1$ & $56 \pm 2$ & $25 \pm 2$ & $22 \pm 1$ & $38 \pm 2$ & $27 \pm 1$ & $27 \pm 2$ \\
\hline 1e & $7 \pm 2$ & $27 \pm 2$ & $30 \pm 2$ & $11 \pm 2$ & $20 \pm 2$ & $39 \pm 2$ & $11 \pm 2$ & $13 \pm 2$ & $56 \pm 2$ & $8 \pm 2$ & $35 \pm 2$ & $33 \pm 1$ & $33 \pm 2$ & $29 \pm 2$ \\
\hline 1f & $29 \pm 1$ & $17 \pm 2$ & $9 \pm 1$ & $34 \pm 2$ & $28 \pm 1$ & $28 \pm 2$ & $30 \pm 1$ & $25 \pm 2$ & $44 \pm 1$ & $4 \pm 2$ & $22 \pm 3$ & $30 \pm 2$ & $40 \pm 2$ & $29 \pm 3$ \\
\hline $1 \mathrm{~g}$ & $37 \pm 2$ & $27 \pm 1$ & $41 \pm 2$ & $47 \pm 1$ & $45 \pm 2$ & $33 \pm 3$ & $22 \pm 2$ & $19 \pm 1$ & $28 \pm 2$ & $8 \pm 2$ & $8 \pm 1$ & $27 \pm 2$ & $40 \pm 2$ & $38 \pm 1$ \\
\hline $1 \mathrm{~h}$ & $17 \pm 1$ & $30 \pm 2$ & $20 \pm 1$ & $20 \pm 2$ & $18 \pm 2$ & $28 \pm 1$ & $19 \pm 2$ & $25 \pm 2$ & $44 \pm 1$ & $8 \pm 2$ & $13 \pm 2$ & $23 \pm 2$ & $20 \pm 3$ & $21 \pm 2$ \\
\hline $1 \mathbf{i}$ & $24 \pm 2$ & $20 \pm 3$ & $4 \pm 2$ & $28 \pm 2$ & $23 \pm 3$ & $28 \pm 2$ & $22 \pm 2$ & $13 \pm 1$ & $52 \pm 2$ & $4 \pm 1$ & $9 \pm 2$ & $8 \pm 1$ & $13 \pm 2$ & $38 \pm 3$ \\
\hline $\mathbf{1 j}$ & $27 \pm 1$ & $40 \pm 2$ & $22 \pm 1$ & $70 \pm 2$ & $30 \pm 2$ & $33 \pm 1$ & $48 \pm 2$ & $19 \pm 2$ & $56 \pm 1$ & $8 \pm 2$ & $9 \pm 2$ & $33 \pm 3$ & $27 \pm 2$ & $29 \pm 1$ \\
\hline $1 k$ & $20 \pm 2$ & $33 \pm 1$ & $54 \pm 2$ & $48 \pm 2$ & $33 \pm 1$ & $33 \pm 2$ & $41 \pm 1$ & $19 \pm 2$ & $44 \pm 2$ & $8 \pm 1$ & $30 \pm 2$ & $33 \pm 1$ & $27 \pm 2$ & $24 \pm 2$ \\
\hline 11 & $15 \pm 1$ & $40 \pm 2$ & 0 & $21 \pm 3$ & $23 \pm 2$ & $25 \pm 1$ & $15 \pm 2$ & $38 \pm 1$ & $32 \pm 2$ & $8 \pm 2$ & $4 \pm 1$ & $56 \pm 2$ & $47 \pm 1$ & $53 \pm 2$ \\
\hline $1 \mathrm{~m}$ & $22 \pm 2$ & $47 \pm 1$ & $26 \pm 2$ & $72 \pm 2$ & $33 \pm 3$ & $44 \pm 2$ & $30 \pm 2$ & $38 \pm 1$ & $36 \pm 2$ & $25 \pm 1$ & $9 \pm 2$ & $33 \pm 1$ & $20 \pm 2$ & $12 \pm 1$ \\
\hline 1n & $22 \pm 1$ & $23 \pm 2$ & $22 \pm 1$ & $42 \pm 2$ & $33 \pm 3$ & $47 \pm 2$ & $30 \pm 1$ & $38 \pm 2$ & $32 \pm 1$ & $8 \pm 2$ & $4 \pm 2$ & $67 \pm 1$ & $27 \pm 2$ & $56 \pm 1$ \\
\hline 10 & $22 \pm 2$ & $30 \pm 1$ & $22 \pm 2$ & $25 \pm 1$ & $30 \pm 2$ & $42 \pm 2$ & $22 \pm 1$ & $31 \pm 2$ & $40 \pm 2$ & $17 \pm 1$ & $4 \pm 2$ & $35 \pm 2$ & $20 \pm 3$ & $21 \pm 2$ \\
\hline $2 a$ & $7 \pm 1$ & $27 \pm 2$ & $28 \pm 3$ & $16 \pm 2$ & $15 \pm 1$ & $25 \pm 2$ & $15 \pm 1$ & $50 \pm 2$ & $68 \pm 1$ & $17 \pm 2$ & $17 \pm 2$ & $11 \pm 1$ & $13 \pm 2$ & $47 \pm 3$ \\
\hline $2 b$ & $12 \pm 2$ & $23 \pm 3$ & $7 \pm 2$ & $20 \pm 1$ & $15 \pm 2$ & $28 \pm 1$ & $11 \pm 2$ & $19 \pm 2$ & $24 \pm 1$ & $13 \pm 2$ & $13 \pm 1$ & $18 \pm 2$ & $17 \pm 1$ & $24 \pm 2$ \\
\hline $2 c$ & $7 \pm 1$ & $67 \pm 2$ & $22 \pm 2$ & $62 \pm 3$ & $35 \pm 2$ & & & & & & & $21 \pm 2$ & $20 \pm 2$ & $47 \pm 3$ \\
\hline $2 d$ & $10 \pm 2$ & $23 \pm 3$ & $33 \pm 2$ & $14 \pm 2$ & $15 \pm 2$ & $14=$ & 15 & 38 & $68 \pm 2$ & & & & & $53 \pm 2$ \\
\hline $2 e$ & $12 \pm 1$ & $27 \pm 2$ & $4 \pm 1$ & $14 \pm 2$ & $10 \pm 1$ & $25 \pm 2$ & $22 \pm 2$ & $6 \pm 2$ & $20 \pm 1$ & $4 \pm 2$ & $9 \pm 1$ & $8 \pm 2$ & & $12 \pm 2$ \\
\hline $15 a$ & $17 \pm 1$ & $40 \pm 2$ & $57 \pm 1$ & $28 \pm 2$ & $23 \pm 1$ & $28 \pm 2$ & $26 \pm 1$ & $19 \pm 2$ & $28 \pm 1$ & $25 \pm 2$ & $57 \pm 1$ & $24 \pm 2$ & $10 \pm 1$ & $24 \pm 2$ \\
\hline $15 b$ & $12 \pm 2$ & $30 \pm 2$ & 0 & $21 \pm 1$ & $23 \pm 2$ & $42 \pm 2$ & $30 \pm 2$ & $38 \pm 3$ & $32 \pm 2$ & $42 \pm 2$ & $52 \pm 2$ & $38 \pm 3$ & $47 \pm 2$ & $50 \pm 1$ \\
\hline $15 \mathrm{c}$ & $12 \pm 1$ & $37 \pm 2$ & $65 \pm 1$ & $32 \pm 2$ & $35 \pm 1$ & $39 \pm 2$ & $37 \pm 1$ & $44 \pm 2$ & $32 \pm 3$ & $33 \pm 2$ & $65 \pm 1$ & $36 \pm 2$ & $47 \pm 1$ & $21 \pm 2$ \\
\hline $15 d$ & $17 \pm 2$ & $50 \pm 1$ & $54 \pm 2$ & $48 \pm 1$ & $33 \pm 2$ & $42 \pm 1$ & $33 \pm 2$ & $50 \pm 2$ & $36 \pm 1$ & $58 \pm 2$ & $74 \pm 3$ & $61 \pm 2$ & $63 \pm 1$ & $50 \pm 2$ \\
\hline water & 0 & 0 & 0 & 0 & 0 & 0 & 0 & 0 & 0 & 0 & 0 & 0 & 0 & 0 \\
\hline chlorothalonil $^{\mathrm{b}}$ & 100 & $73 \pm 2$ & 100 & $73 \pm 1$ & $<50$ & 100 & $<50$ & 100 & 100 & $91 \pm 1$ & $91 \pm 2$ & $86 \pm 3$ & 100 & 100 \\
\hline carbendazim $^{\mathrm{b}}$ & $<50$ & $<50$ & $<50$ & $<50$ & 100 & $<50$ & 100 & $<50$ & 100 & 100 & 100 & 100 & 100 & $<50$ \\
\hline
\end{tabular}

a Average of three replicates. ${ }^{\mathrm{b}}$ The commercial agricultural fungicides chlorothalonil and carbendazim were used for comparison of antifungal activity. ${ }^{\mathrm{c}}$ F.C, Fusarium oxysporium $f$. sp. cucumeris; C.H, Cercospora arachidicola Hori; P.P, Physalospora piricola; R.C, Rhizoctonia cerealis; B.M. Bipolaris maydis; W. A, watermelon anthracnose; F.M, Fusarium moniliforme; A.S, Alternaria solani; F.G, Fusarium graminearum; P.I,Phytophthora infestans; P.C, Phytophthora capsici; S.S, Sclerotinia sclerotiorum; R.S, Rhizoctonia solani; B.C, Botrytis cinerea. 


\subsubsection{In Vivo Fungicidal Activity}

The activities of compounds 1, $\mathbf{2}$ and $\mathbf{1 5}$ were also evaluated in vivo against Sclerotinia sclerotiorum on rape, Rhizoctonia cerealis on cerealis, Botrytis cinerea on cucumber, Phytophthora capsici on capsici, Corynespora cassiicola on cucumber, and Blum eria graminis f. sp. tritici on wheat (Table 3). The assays revealed that many of the compounds had an inhibitory effect of $>30 \%$. Compounds $15 \mathbf{b}-\mathbf{d}$ exhibited greater inhibitory effects against Phytophthora capsici on capsici than did naamines $\mathbf{1}$ and naamidines $\mathbf{2}$. However, none of the compounds showed an inhibitory effect against Blumeria graminis $f$. sp. tritici on wheat.

Table 3. In vivo fungicidal activities of 1a-o, 2a-e and 15a-d against 6 kinds of Fungi.

\begin{tabular}{|c|c|c|c|c|c|c|}
\hline \multirow{2}{*}{ Compound } & \multicolumn{6}{|c|}{ Inhibition Rate $(\%) b / 200 \mu \mathrm{g} / \mathrm{mL}$} \\
\hline & S.S a & R.C & B.C & P.C & C.C & B.G \\
\hline $1 a$ & $25 \pm 2$ & $28 \pm 1$ & $27 \pm 2$ & $15 \pm 2$ & $36 \pm 1$ & 0 \\
\hline $1 b$ & $15 \pm 2$ & $28 \pm 2$ & $9 \pm 2$ & $20 \pm 1$ & $25 \pm 2$ & 0 \\
\hline $1 c$ & $13 \pm 1$ & $17 \pm 2$ & $9 \pm 2$ & $10 \pm 2$ & $36 \pm 2$ & 0 \\
\hline 1d & $10 \pm 2$ & $11 \pm 2$ & $18 \pm 2$ & $20 \pm 1$ & $15 \pm 2$ & 0 \\
\hline 1e & $10 \pm 2$ & $17 \pm 1$ & $9 \pm 2$ & $30 \pm 2$ & $18 \pm 2$ & 0 \\
\hline 1f & $13 \pm 2$ & $28 \pm 2$ & $9 \pm 1$ & $25 \pm 2$ & $32 \pm 1$ & 0 \\
\hline $1 \mathrm{~g}$ & $10 \pm 1$ & $32 \pm 2$ & $18 \pm 2$ & $15 \pm 2$ & $36 \pm 2$ & 0 \\
\hline $1 \mathrm{~h}$ & $8 \pm 2$ & $11 \pm 1$ & $18 \pm 2$ & $15 \pm 2$ & $15 \pm 1$ & 0 \\
\hline $1 \mathbf{i}$ & $8 \pm 2$ & $6 \pm 2$ & $27 \pm 2$ & $15 \pm 1$ & $11 \pm 2$ & 0 \\
\hline $\mathbf{1 j}$ & $19 \pm 2$ & $11 \pm 1$ & $27 \pm 2$ & $10 \pm 2$ & $11 \pm 2$ & 0 \\
\hline $1 \mathrm{k}$ & $21 \pm 2$ & $22 \pm 2$ & $9 \pm 1$ & $30 \pm 2$ & $18 \pm 2$ & 0 \\
\hline 11 & $27 \pm 1$ & $17 \pm 2$ & $27 \pm 1$ & $5 \pm 2$ & $25 \pm 2$ & 0 \\
\hline $1 \mathrm{~m}$ & $10 \pm 2$ & $6 \pm 2$ & $9 \pm 2$ & $10 \pm 1$ & $15 \pm 2$ & 0 \\
\hline 1n & $27 \pm 1$ & $6 \pm 2$ & $18 \pm 1$ & $5 \pm 2$ & $21 \pm 2$ & 0 \\
\hline 10 & $27 \pm 2$ & $28 \pm 2$ & $9 \pm 2$ & $10 \pm 2$ & $15 \pm 1$ & 0 \\
\hline $2 a$ & $8 \pm 2$ & $28 \pm 1$ & $27 \pm 2$ & $10 \pm 2$ & $25 \pm 2$ & 0 \\
\hline $2 b$ & $8 \pm 2$ & $11 \pm 2$ & $9 \pm 2$ & $15 \pm 2$ & $11 \pm 2$ & 0 \\
\hline $2 c$ & $19 \pm 2$ & $17 \pm 1$ & $18 \pm 2$ & $15 \pm 1$ & $32 \pm 2$ & 0 \\
\hline $2 d$ & $10 \pm 1$ & $17 \pm 2$ & $18 \pm 1$ & $20 \pm 2$ & $18 \pm 1$ & 0 \\
\hline $2 e$ & $8 \pm 2$ & $22 \pm 1$ & $9 \pm 2$ & $10 \pm 1$ & $32 \pm 2$ & 0 \\
\hline $15 a$ & $27 \pm 2$ & $17 \pm 1$ & $9 \pm 2$ & $25 \pm 1$ & $15 \pm 2$ & 0 \\
\hline $15 b$ & $27 \pm 1$ & $32 \pm 2$ & $27 \pm 1$ & $40 \pm 2$ & $25 \pm 1$ & 0 \\
\hline $15 c$ & $19 \pm 2$ & $25 \pm 1$ & $18 \pm 2$ & $40 \pm 1$ & $36 \pm 2$ & 0 \\
\hline $15 d$ & $35 \pm 1$ & $32 \pm 2$ & $27 \pm 1$ & $40 \pm 2$ & $15 \pm 1$ & 0 \\
\hline water & 0 & 0 & 0 & 0 & 0 & 0 \\
\hline azoxystrobin $^{\mathrm{c}}$ & 100 & 100 & 100 & $83 \pm 2$ & $81 \pm 1$ & $82 \pm 2$ \\
\hline
\end{tabular}

\section{Experimental Section}

\subsection{General Experimental Procedures}

The melting points were determined on an X-4 binocular microscope (Beijing Tech Instruments Co., Beijing, China). NMR spectra were obtained by using Bruker AV 400 spectrometer (Bruker Co., Fallanden, Switzerland). Chemical shifts $(\delta)$ were given in parts per million (ppm) and measured downfield from internal tetramethylsilane. High-resolution mass spectra were obtained with an FT-ICR MS spectrometer (Ionspec, 7.0 T, Kuala Lumpur, Malaysia). All reagents were of analytical reagent grade or chemically pure and purified prior to use when necessary.

See Supplementary Materials for all NMR spectra.

General procedure for the preparation of benzaldehydes 4 . The mixture of benzaldehydes 3 (0.06 mol), $\mathrm{K}_{2} \mathrm{CO}_{3}(11.0 \mathrm{~g}, 0.07 \mathrm{~mol})$, benzyl bromide $(9.4 \mathrm{~g}, 0.07 \mathrm{~mol})$ and methanol $250 \mathrm{~mL}$ was 
stirred and refluxed for $4 \mathrm{~h}$ under argon. Then the reaction mixture was filtered and evaporated under vacuum. The residue was dissolved in $\mathrm{CH}_{2} \mathrm{Cl}_{2}(200 \mathrm{~mL})$ and washed with $\mathrm{H}_{2} \mathrm{O}(100 \mathrm{~mL})$, brine $(100 \mathrm{~mL})$, and dried with $\mathrm{MgSO}_{4}$ anhydrous. The solution was filtered, evaporated under vacuum. Then acetone $(10 \mathrm{~mL})$ was added. The mixture was kept at $0{ }^{\circ} \mathrm{C}$ for $4 \mathrm{~h}$, filtered to give benzaldehydes 4 as a white powder.

For 4-(benzyloxy)-3-methoxybenzaldehyde (4a): Yield 85\%; m.p.: 67-68 ${ }^{\circ} \mathrm{C} ;{ }^{1} \mathrm{H} \mathrm{NMR}\left(400 \mathrm{MHz}, \mathrm{CDCl}_{3}\right)$ $\delta 9.83(\mathrm{~s}, 1 \mathrm{H}, \mathrm{COH}), 7.45-7.31(\mathrm{~m}, 7 \mathrm{H}, \mathrm{Ar}-\mathrm{H}), 6.99(\mathrm{~d}, J=8.2 \mathrm{~Hz}, 1 \mathrm{H}, \mathrm{Ar}-\mathrm{H}), 5.25\left(\mathrm{~s}, 2 \mathrm{H}, \mathrm{O}-\mathrm{CH}_{2}\right), 3.95$ $\left(\mathrm{s}, 3 \mathrm{H}, \mathrm{O}-\mathrm{CH}_{3}\right)$.

For 3-(benzyloxy)-4-methoxybenzaldehyde (4b): Yield 95\%; m.p.: $63-65{ }^{\circ} \mathrm{C} ;{ }^{1} \mathrm{H}$ NMR $(400 \mathrm{MHz}$, $\left.\mathrm{CDCl}_{3}\right) \delta 9.82(\mathrm{~s}, 1 \mathrm{H}, \mathrm{COH}), 7.47-7.30(\mathrm{~m}, 7 \mathrm{H}, \mathrm{Ar}-\mathrm{H}), 6.99(\mathrm{~d}, J=8.1 \mathrm{~Hz}, 1 \mathrm{H}, \mathrm{Ar}-\mathrm{H}), 5.19\left(\mathrm{~s}, 2 \mathrm{H}, \mathrm{O}-\mathrm{CH}_{2}\right)$, $3.96\left(\mathrm{~s}, 3 \mathrm{H}, \mathrm{O}-\mathrm{CH}_{3}\right)$.

For 4-(benzyloxy)-3,5-dimethoxybenzaldehyde (4c): Yield 88\%; m.p.: $63-64{ }^{\circ} \mathrm{C} ;{ }^{1} \mathrm{H}$ NMR $(400 \mathrm{MHz}$, $\left.\mathrm{CDCl}_{3}\right) \delta 9.86(\mathrm{~s}, 1 \mathrm{H}, \mathrm{COH}), 7.47(\mathrm{~d}, J=7.1 \mathrm{~Hz}, 2 \mathrm{H}, \mathrm{Ar}-\mathrm{H}), 7.32(\mathrm{dd}, J=11.2,7.0 \mathrm{~Hz}, 3 \mathrm{H}, \mathrm{Ar}-\mathrm{H}), 7.11$ (s, 2H, Ar-H), 5.13 (s, 2H, O-CH $\mathrm{CH}_{2}, 3.90\left(\mathrm{~s}, 6 \mathrm{H}, \mathrm{O}-\mathrm{CH}_{3}\right)$.

General procedure for the preparation of 5 . The mixture of benzaldehydes $4(0.02 \mathrm{~mol})$, acetic anhydride $(10 \mathrm{~mL}), \mathrm{N}$-acetyl-glycine $(0.02 \mathrm{~mol})$ and sodium acetate $(0.02 \mathrm{~mol})$ was stirred at $115^{\circ} \mathrm{C}$ for $3.5 \mathrm{~h}$ under argon. Then, the reaction mixture was cooled to room temperature, and ethanol $(100 \mathrm{~mL})$ was added. After ultrasonic oscillation, the mixture was filtered to give 5 as a yellow powder.

For (Z)-4-(4-(benzyloxy)-3-methoxybenzylidene)-2-methyloxazol-5(4H)-one (5a): Yield 44\%; m.p.: 157-159 ${ }^{\circ} \mathrm{C} ;{ }^{1} \mathrm{H}$ NMR $\left(400 \mathrm{MHz}, \mathrm{CDCl}_{3}\right) \delta 7.92(\mathrm{~d}, J=1.8 \mathrm{~Hz}, 1 \mathrm{H}, \mathrm{Ar}-\mathrm{H}), 7.48-7.29(\mathrm{~m}, 6 \mathrm{H}, \mathrm{Ar}-\mathrm{H}), 7.07$ $(\mathrm{s}, 1 \mathrm{H}, \mathrm{CH}), 6.91(\mathrm{~d}, \mathrm{~J}=8.4 \mathrm{~Hz}, 1 \mathrm{H}, \mathrm{Ar}-\mathrm{H}), 5.23\left(\mathrm{~s}, 2 \mathrm{H}, \mathrm{O}-\mathrm{CH}_{2}\right), 3.96\left(\mathrm{~s}, 3 \mathrm{H}, \mathrm{O}-\mathrm{CH}_{3}\right), 2.39\left(\mathrm{~s}, 3 \mathrm{H}, \mathrm{C}-\mathrm{CH}_{3}\right)$.

For (Z)-4-(3-(benzyloxy)-4-methoxybenzylidene)-2-methyloxazol-5(4H)-one (5b): Yield 28\%; m.p.: 108-110 ${ }^{\circ} \mathrm{C} ;{ }^{1} \mathrm{H}$ NMR $\left(400 \mathrm{MHz}, \mathrm{CDCl}_{3}\right) \delta 7.99$ (s, 1H, CH), 7.52-7.28 (m, 6H, Ar-H), 7.03 (s, 1H, Ar-H), $6.92(\mathrm{~d}, J=8.4 \mathrm{~Hz}, 1 \mathrm{H}, \mathrm{Ar}-\mathrm{H}), 5.22\left(\mathrm{~s}, 2 \mathrm{H}, \mathrm{O}-\mathrm{CH}_{2}\right), 3.94\left(\mathrm{~s}, 3 \mathrm{H}, \mathrm{O}-\mathrm{CH}_{3}\right), 2.39\left(\mathrm{~s}, 3 \mathrm{H}, \mathrm{C}-\mathrm{CH}_{3}\right) ;{ }^{13} \mathrm{C} \mathrm{NMR}$ $\left(100 \mathrm{MHz}, \mathrm{CDCl}_{3}\right) \delta 168.1,164.8,152.6,148.2,136.7,131.6,130.5,128.6,128.0,127.6,126.3,116.4,111.3$, 71.0, 56.0, 15.6; HRMS (ESI) calcd. for $\mathrm{C}_{19} \mathrm{H}_{18} \mathrm{NO}_{4}{ }^{+}[\mathrm{M}+\mathrm{H}]^{+}$324.1230, found 324.1232.

For (Z)-4-(4-(benzyloxy)-3,5-dimethoxybenzylidene)-2-methyloxazol-5(4H)-one (5c): Yield 52\%; m.p.: 102-104 ${ }^{\circ} \mathrm{C} ;{ }^{1} \mathrm{H}$ NMR $\left(400 \mathrm{MHz}, \mathrm{CDCl}_{3}\right) \delta 7.48(\mathrm{~d}, J=7.5 \mathrm{~Hz}, 2 \mathrm{H}, \mathrm{Ar}-\mathrm{H}), 7.41-7.28(\mathrm{~m}, 5 \mathrm{H}, \mathrm{Ar}-\mathrm{H}), 7.04$ $(\mathrm{s}, 1 \mathrm{H}, \mathrm{CH}), 5.10\left(\mathrm{~s}, 2 \mathrm{H}, \mathrm{O}-\mathrm{CH}_{2}\right), 3.88\left(\mathrm{~s}, 6 \mathrm{H}, \mathrm{O}-\mathrm{CH}_{3}\right), 2.40\left(\mathrm{~s}, 3 \mathrm{H}, \mathrm{C}-\mathrm{CH}_{3}\right) ;{ }^{13} \mathrm{C} \mathrm{NMR}\left(100 \mathrm{MHz}, \mathrm{CDCl}_{3}\right)$ $\delta 167.9,165.6,153.6,139.9,137.4,131.6,131.5,128.7,128.5,128.2,128.0,109.6,75.1,56.2,15.8$; HRMS (ESI) calcd. for $\mathrm{C}_{20} \mathrm{H}_{20} \mathrm{NO}_{5}{ }^{+}[\mathrm{M}+\mathrm{H}]^{+} 354.1336$, found 354.1338.

General procedure for the preparation of acids 6. The mixture of $5(13.10 \mathrm{mmol}), \mathrm{NaOH}(1.6 \mathrm{~g}$, $39.20 \mathrm{mmol})$ and $\mathrm{H}_{2} \mathrm{O}(100 \mathrm{~mL})$ was stirred and refluxed for $1 \mathrm{~h}$. Then, the reaction mixture was cooled to room temperature and acidified to $\mathrm{pH} 5-6$ with dilute hydrochloric acid. The mixture was filtered to give acids 6 as a white powder.

For (Z)-2-acetamido-3-(4-(benzyloxy)-3-methoxyphenyl)acrylic acid (6a): Yield 93\%; m.p.: 200-202 ${ }^{\circ} \mathrm{C}$; ${ }^{1} \mathrm{H}$ NMR $\left(400 \mathrm{MHz}, \mathrm{DMSO}-d_{6}\right) \delta 12.52(\mathrm{~s}, 1 \mathrm{H}, \mathrm{COOH}), 9.41(\mathrm{~s}, 1 \mathrm{H}, \mathrm{NH}), 7.45-7.35$ (m, 5H, Ar-H), 7.33 (s, 1H, Ar-H), $7.21(\mathrm{~s}, 1 \mathrm{H}, \mathrm{CH}), 7.18(\mathrm{~d}, J=8.4 \mathrm{~Hz}, 1 \mathrm{H}, \mathrm{Ar}-\mathrm{H}), 7.07$ (d, J = 8.4 Hz, 1H, Ar-H), 5.13 (s, 2H, $\left.\mathrm{O}-\mathrm{CH}_{2}\right), 3.77\left(\mathrm{~s}, 3 \mathrm{H}, \mathrm{O}-\mathrm{CH}_{3}\right), 1.99\left(\mathrm{~s}, 3 \mathrm{H}, \mathrm{C}-\mathrm{CH}_{3}\right)$.

For (Z)-2-acetamido-3-(3-(benzyloxy)-4-methoxyphenyl)acrylic acid (6b): Yield 61\%; m.p.: 209-211 ${ }^{\circ} \mathrm{C}$; ${ }^{1} \mathrm{H}$ NMR (400 MHz, DMSO) $\delta 12.53(\mathrm{~s}, 1 \mathrm{H}, \mathrm{COOH}), 9.46(\mathrm{~s}, 1 \mathrm{H}, \mathrm{NH}), 7.55-7.30(\mathrm{~m}, 6 \mathrm{H}, \mathrm{Ar}-\mathrm{H}), 7.24(\mathrm{~d}$, $J=8.2 \mathrm{~Hz}, 1 \mathrm{H}, \mathrm{Ar}-\mathrm{H}), 7.19(\mathrm{~s}, 1 \mathrm{H}, \mathrm{CH}), 7.02(\mathrm{~d}, J=8.2 \mathrm{~Hz}, 1 \mathrm{H}, \mathrm{Ar}-\mathrm{H}), 5.10\left(\mathrm{~s}, 2 \mathrm{H}, \mathrm{O}-\mathrm{CH}_{2}\right), 3.80(\mathrm{~s}, 3 \mathrm{H}$, $\left.\mathrm{O}-\mathrm{CH}_{3}\right), 1.97\left(\mathrm{~s}, 3 \mathrm{H}, \mathrm{CO}-\mathrm{CH}_{3}\right)$.

For (Z)-2-acetamido-3-(4-(benzyloxy)-3,5-dimethoxyphenyl)acrylic acid (6c): Yield 53\%; m.p.: 155-157 ${ }^{\circ} \mathrm{C} ;{ }^{1} \mathrm{H}$ NMR $\left(400 \mathrm{MHz}, \mathrm{CD}_{3} \mathrm{OD}\right) \delta 7.46(\mathrm{~s}, 1 \mathrm{H}, \mathrm{CH}), 7.44(\mathrm{~d}, J=6.7 \mathrm{~Hz}, 2 \mathrm{H}, \mathrm{Ar}-\mathrm{H}), 7.36-7.24(\mathrm{~m}, 3 \mathrm{H}$, 
Ar-H), 6.93 (s, 2H, Ar-H), 4.99 (s, 2H, O-CH $), 3.82\left(\mathrm{~s}, 6 \mathrm{H}, \mathrm{O}-\mathrm{CH}_{3}\right), 2.11$ (s, 3H, CO-CH 3$) ;{ }^{13} \mathrm{C} \mathrm{NMR}$ $\left(100 \mathrm{MHz}, \mathrm{CD}_{3} \mathrm{OD}\right) \delta 173.2,168.3,154.7,139.2,139.0,136.0,130.7,129.6,129.2,129.1,126.2,108.5,76.1$, 56.6, 22.6; HRMS (ESI) calcd. for $\mathrm{C}_{20} \mathrm{H}_{22} \mathrm{NO}_{6}{ }^{+}[\mathrm{M}+\mathrm{H}]^{+} 372.1442$, found 372.1444.

General procedure for the preparation of acids 7 . The mixture of acids $6(3.28 \mathrm{mmol})$ and $\mathrm{Pd} / \mathrm{C}$ $(10 \mathrm{wt} \%)(0.15 \mathrm{~g})$ in ethanol $(100 \mathrm{~mL})$ was bubbled with hydrogen and stirred at room temperature for $12 \mathrm{~h}$. Then, the mixture was filtered and concentrated to give acids 7 as a slight yellow powder.

For 2-acetamido-3-(4-(benzyloxy)-3-methoxyphenyl)propanoic acid (7a): Yield 98\%; m.p.: 73-75 ${ }^{\circ} \mathrm{C}$; ${ }^{1} \mathrm{H}$ NMR $\left(400 \mathrm{MHz}, \mathrm{CD}_{3} \mathrm{OD}\right) \delta 6.79(\mathrm{~d}, J=1.8 \mathrm{~Hz}, 1 \mathrm{H}, \mathrm{Ar}-\mathrm{H}), 6.70(\mathrm{~d}, J=8.0 \mathrm{~Hz}, 1 \mathrm{H}, \mathrm{Ar}-\mathrm{H}), 6.64(\mathrm{dd}$, $J=8.0,1.8 \mathrm{~Hz}, 1 \mathrm{H}, \mathrm{Ar}-\mathrm{H}), 4.61(\mathrm{dd}, J=8.9,5.1 \mathrm{~Hz}, 1 \mathrm{H}, \mathrm{CH}), 3.82\left(\mathrm{~s}, 3 \mathrm{H}, \mathrm{O}-\mathrm{CH}_{3}\right), 3.10(\mathrm{dd}, J=14.0$, $\left.5.1 \mathrm{~Hz}, 1 \mathrm{H}, \mathrm{CH}_{2}\right), 2.85\left(\mathrm{dd}, \mathrm{J}=14.0,8.9 \mathrm{~Hz}, 1 \mathrm{H}, \mathrm{CH}_{2}\right), 1.91\left(\mathrm{~s}, 3 \mathrm{H}, \mathrm{C}-\mathrm{CH}_{3}\right)$.

For 2-acetamido-3-(3-(benzyloxy)-4-methoxyphenyl)propanoic acid (7b): Yield 95\%; m.p.: 147-150 ${ }^{\circ} \mathrm{C}$; ${ }^{1} \mathrm{H}$ NMR $\left(400 \mathrm{MHz}, \mathrm{CD}_{3} \mathrm{OD}\right) \delta 6.82(\mathrm{~d}, J=8.0 \mathrm{~Hz}, 1 \mathrm{H}, \mathrm{Ar}-\mathrm{H}), 6.69(\mathrm{~s}, 1 \mathrm{H}, \mathrm{Ar}-\mathrm{H}), 6.65(\mathrm{~d}, J=8.0 \mathrm{~Hz}$, $1 \mathrm{H}, \mathrm{Ar}-\mathrm{H}), 4.57(\mathrm{dd}, J=8.7,5.0 \mathrm{~Hz}, 1 \mathrm{H}, \mathrm{CH}), 3.81\left(\mathrm{~s}, 3 \mathrm{H}, \mathrm{O}-\mathrm{CH}_{3}\right), 3.06\left(\mathrm{dd}, J=13.9,5.0 \mathrm{~Hz}, 1 \mathrm{H}, \mathrm{CH}_{2}\right)$, $2.82\left(\mathrm{dd}, J=13.9,8.7 \mathrm{~Hz}, 1 \mathrm{H}, \mathrm{CH}_{2}\right), 1.91\left(\mathrm{~s}, 3 \mathrm{H}, \mathrm{CO}-\mathrm{CH}_{3}\right) ;{ }^{13} \mathrm{C} \mathrm{NMR}\left(100 \mathrm{MHz}, \mathrm{CD}_{3} \mathrm{OD}\right) \delta 174.9,173.2$, 148.0, 147.4, 131.2, 121.5, 117.2, 112.7, 56.4, 55.4, 37.8, 22.4; HRMS (ESI) calcd. for $\mathrm{C}_{12} \mathrm{H}_{16} \mathrm{NO}_{5}{ }^{+}[\mathrm{M}+\mathrm{H}]^{+}$ 254.1023, found 254.1019.

For 2-acetamido-3-(4-(benzyloxy)-3,5-dimethoxyphenyl)propanoic acid (7c): Yield 96\%; m.p.: 148-151 ${ }^{\circ} \mathrm{C} ;{ }^{1} \mathrm{H}$ NMR $\left(400 \mathrm{MHz}, \mathrm{CD}_{3} \mathrm{OD}\right) \delta 6.54(\mathrm{~s}, 2 \mathrm{H}, \mathrm{Ar}-\mathrm{H}), 4.68(\mathrm{dd}, J=8.8,5.0 \mathrm{~Hz}, 1 \mathrm{H}, \mathrm{CH})$, $3.86\left(\mathrm{~s}, 6 \mathrm{H}, \mathrm{O}-\mathrm{CH}_{3}\right), 3.16\left(\mathrm{dd}, J=13.9,5.0 \mathrm{~Hz}, 1 \mathrm{H}, \mathrm{CH}_{2}\right), 2.90\left(\mathrm{dd}, J=13.9,8.8 \mathrm{~Hz}, 1 \mathrm{H}, \mathrm{CH}_{2}\right), 1.97(\mathrm{~s}, 3 \mathrm{H}$, CO-CH 3$) ;{ }^{13} \mathrm{C}$ NMR $\left(100 \mathrm{MHz}, \mathrm{CD}_{3} \mathrm{OD}\right) \delta 175.0,173.2,149.2,135.4,129.0,107.4,56.8,55.4,38.6,22.4$; HRMS (ESI) calcd. for $\mathrm{C}_{13} \mathrm{H}_{18} \mathrm{NO}_{6}{ }^{+}[\mathrm{M}+\mathrm{H}]^{+} 284.1129$, found 284.1133 .

General procedure for the preparation of amino acids 8 . The mixture of acids 7 (19.78 mmol) in $4 \mathrm{~N} \mathrm{HCl}$ solution $(500 \mathrm{~mL})$ was refluxed for $24 \mathrm{~h}$ and concentrated. Then, methanol $(50 \mathrm{~mL})$ was added. The mixture was kept at $0{ }^{\circ} \mathrm{C}$ for $4 \mathrm{~h}$, filtered to give amino acids 8 , which were used directly for the next step.

General procedure for the preparation of amino acids $\mathbf{9}$. The mixture of acids 8 (4.03 mmol), (Boc) $)_{2} \mathrm{O}(4.44 \mathrm{mmol}), \mathrm{Et}_{3} \mathrm{~N}(12.1 \mathrm{mmol}), \mathrm{H}_{2} \mathrm{O}(20 \mathrm{~mL})$ and 1,4-dioxane $(20 \mathrm{~mL})$ was stirred at room temperature for $18 \mathrm{~h}$. Then, the mixture was concentrated and dissolved in $\mathrm{H}_{2} \mathrm{O}(100 \mathrm{~mL})$, acidified to pH 5-6 with dilute hydrochloric acid, and extracted with ethyl acetate $(100 \mathrm{~mL} \times 3)$. The combined organic layer was washed with brine $(100 \mathrm{~mL})$, dried with $\mathrm{MgSO}_{4}$ anhydrous. The solution was filtered, evaporated under vacuum. Methanol $(10 \mathrm{~mL})$ was added. The mixture was kept at $0{ }^{\circ} \mathrm{C}$ for $4 \mathrm{~h}$, filtered to give amino acids $\mathbf{9}$, which were used directly for the next step.

General procedure for the preparation of Boc amino acids 10. The mixture of amino acids 9 (1.89 mmol), $\mathrm{K}_{2} \mathrm{CO}_{3}(4.55 \mathrm{mmol})$, benzyl bromide $(2.27 \mathrm{mmol})$ and methanol $(50 \mathrm{~mL})$ was refluxed for $4 \mathrm{~h}$. Then, the mixture was concentrated and dissolved in $\mathrm{H}_{2} \mathrm{O}(50 \mathrm{~mL})$, acidified to $\mathrm{pH}$ 5-6 with dilute hydrochloric acid, and extracted with ethyl acetate $(50 \mathrm{~mL} \times 3)$. The combined organic layer was washed with brine $(100 \mathrm{~mL})$, dried with $\mathrm{MgSO}_{4}$ anhydrous. The solution was filtered, evaporated under vacuum to give Boc amino acids $\mathbf{1 0}$.

For 3-(4-(benzyloxy)-3-methoxyphenyl)-2-((tert-butoxycarbonyl)amino)propanoic acid (10a): Slight yellow powder; Yield for three steps $68 \%$; m.p.: $128-130{ }^{\circ} \mathrm{C}^{1}{ }^{1} \mathrm{H} \mathrm{NMR}\left(400 \mathrm{MHz}, \mathrm{CDCl}_{3}\right.$, exists as a complex mixture of two rotamers at room temperature) $\delta 7.51-7.27(\mathrm{~m}, 5 \mathrm{H}, \mathrm{Ar}-\mathrm{H}), 6.81(\mathrm{~d}, J=8.1 \mathrm{~Hz}$, 1H, Ar-H), $6.72(\mathrm{~s}, 1 \mathrm{H}, \mathrm{Ar}-\mathrm{H}), 6.65(\mathrm{~d}, J=7.8 \mathrm{~Hz}, 1 \mathrm{H}, \mathrm{Ar}-\mathrm{H}), 6.02$ and $4.93(\mathrm{~d}, J=7.3 \mathrm{~Hz}, 1 \mathrm{H}, \mathrm{NH}), 5.12$ $\left(\mathrm{s}, 2 \mathrm{H}, \mathrm{O}-\mathrm{CH}_{2}\right), 4.55$ and $4.34(\mathrm{~s}, 1 \mathrm{H}, \mathrm{CH}), 3.85\left(\mathrm{~s}, 3 \mathrm{H}, \mathrm{O}-\mathrm{CH}_{3}\right), 3.13-2.85\left(\mathrm{~m}, 2 \mathrm{H}, \mathrm{CH}_{2}\right), 1.42$ and 1.32 (two s, 9H, C-CH ). $^{2}$.

For 3-(3-(benzyloxy)-4-methoxyphenyl)-2-((tert-butoxycarbonyl)amino)propanoic acid (10b): White powder; Yield for three steps 53\%; m.p.: $143-145^{\circ} \mathrm{C} ;{ }^{1} \mathrm{H}$ NMR $\left(400 \mathrm{MHz}, \mathrm{CDCl}_{3}\right.$, exists as a complex mixture of two rotamers at room temperature) $\delta 7.46-7.28(\mathrm{~m}, 5 \mathrm{H}, \mathrm{Ar}-\mathrm{H}), 6.81(\mathrm{~d}, J=8.6 \mathrm{~Hz}, 1 \mathrm{H}, \mathrm{Ar}-\mathrm{H})$, 
6.75-6.68 (m, 2H, Ar-H), 5.84 and 4.89 (two d, $1 \mathrm{H}, \mathrm{NH}), 5.11\left(\mathrm{~s}, 2 \mathrm{H}, \mathrm{O}-\mathrm{CH}_{2}\right), 4.59-4.46$ and 4.35-4.25 (two $\left.\mathrm{m}, 1 \mathrm{H}, \mathrm{CHCH}_{2}\right), 3.85\left(\mathrm{~s}, 3 \mathrm{H}, \mathrm{O}-\mathrm{CH}_{3}\right), 3.12-2.76\left(\mathrm{~m}, 2 \mathrm{H}, \mathrm{CHCH}_{2}\right), 1.42$ and 1.35 (two s, 9H, C- $\mathrm{CH}_{3}$ ).

For 3-(4-(benzyloxy)-3,5-dimethoxyphenyl)-2-((tert-butoxycarbonyl)amino)propanoic acid (10c): Brown powder; Yield for three steps $23 \%$; m.p.: $123-125{ }^{\circ} \mathrm{C} ;{ }^{1} \mathrm{H} \mathrm{NMR}\left(400 \mathrm{MHz}, \mathrm{CDCl}_{3}\right.$, exists as a complex mixture of two rotamers at room temperature) $\delta 7.47(\mathrm{~d}, J=7.1 \mathrm{~Hz}, 2 \mathrm{H}, \mathrm{Ar}-\mathrm{H}), 7.36-7.27$ $(\mathrm{m}, 3 \mathrm{H}, \mathrm{Ar}-\mathrm{H}), 6.38(\mathrm{~s}, 2 \mathrm{H}, \mathrm{Ar}-\mathrm{H}), 4.98\left(\mathrm{~s}, 2 \mathrm{H}, \mathrm{O}-\mathrm{CH}_{2}\right), 4.94(\mathrm{~d}, \mathrm{~J}=6.9 \mathrm{~Hz}, 1 \mathrm{H}, \mathrm{NH}), 4.59(\mathrm{~s}, 1 \mathrm{H}, \mathrm{CH})$, $3.79\left(\mathrm{~s}, 6 \mathrm{H}, \mathrm{O}-\mathrm{CH}_{3}\right), 3.18-3.08\left(\mathrm{~m}, 1 \mathrm{H}, \mathrm{CH}_{2}\right), 3.05-2.96\left(\mathrm{~m}, 1 \mathrm{H}, \mathrm{CH}_{2}\right), 1.43$ and 1.35 (two s, 9H, C-CH ${ }_{3}$ ).

For 3-(4-(benzyloxy)phenyl)-2-((tert-butoxycarbonyl)amino)propanoic acid (10d): White powder; Yield for three steps $93 \%$; m.p.: $110-11{ }^{\circ} \mathrm{C} ;{ }^{1} \mathrm{H}$ NMR $\left(400 \mathrm{MHz}, \mathrm{CDCl}_{3}\right) \delta 7.45-7.28(\mathrm{~m}, 5 \mathrm{H}, \mathrm{Ar}-\mathrm{H}), 7.10(\mathrm{~d}$, $J=8.3 \mathrm{~Hz}, 2 \mathrm{H}, \mathrm{Ar}-\mathrm{H}), 6.91(\mathrm{~d}, J=8.4 \mathrm{~Hz}, 2 \mathrm{H}, \mathrm{Ar}-\mathrm{H}), 6.11$ and $4.92($ two d, $J=6.6 \mathrm{~Hz}, 1 \mathrm{H}, \mathrm{NH}), 5.03$ (s, $\left.2 \mathrm{H}, \mathrm{O}-\mathrm{CH}_{2}\right), 4.57$ and $4.36\left(\right.$ two d, $\left.J=5.4 \mathrm{~Hz}, 1 \mathrm{H}, \mathrm{CHCH}_{2}\right), 3.06\left(\mathrm{~m}, 2 \mathrm{H}, \mathrm{CHCH}_{2}\right), 1.37(\mathrm{~d}, J=38.4 \mathrm{~Hz}$, $\left.9 \mathrm{H}, \mathrm{CCH}_{3}\right)$.

General procedure for the preparation of acids 11. To the solution of acids $\mathbf{1 0}(10.02 \mathrm{mmol})$ in THF $(30 \mathrm{~mL})$ was added $70 \% \mathrm{NaH}(30.06 \mathrm{mmol})$ and stirred for $30 \mathrm{~min}$ at $0{ }^{\circ} \mathrm{C}$. Then $\mathrm{CH}_{3} \mathrm{I}(20.04 \mathrm{mmol})$ was added. The reaction mixture was stirred for $24 \mathrm{~h}$ at room temperature, and quenched with $\mathrm{H}_{2} \mathrm{O}$ $(20 \mathrm{~mL})$, and extracted with ethyl acetate $(100 \mathrm{~mL} \times 3)$. The combined organic layer was washed with $\mathrm{Na}_{2} \mathrm{~S}_{2} \mathrm{O}_{3}$ solution $(100 \mathrm{~mL}), \mathrm{NaHCO}_{3}$ solution $(100 \mathrm{~mL})$, brine $(100 \mathrm{~mL})$ and dried with $\mathrm{MgSO}_{4}$ anhydrous. The solution was filtered, evaporated under vacuum to give acids $\mathbf{1 1}$.

For 3-(4-(benzyloxy)-3-methoxyphenyl)-2-((tert-butoxycarbonyl)(methyl)amino)propanoic acid (11a): Yellow oil; Yield $88 \% ;{ }^{1} \mathrm{H}$ NMR ( $400 \mathrm{MHz}, \mathrm{CDCl}_{3}$, exists as a complex mixture of two rotamers at room temperature) $\delta 7.47-7.27(\mathrm{~m}, 5 \mathrm{H}, \mathrm{Ar}-\mathrm{H}), 6.83-6.62(\mathrm{~m}, 3 \mathrm{H}, \mathrm{Ar}-\mathrm{H}), 5.12\left(\mathrm{~s}, 2 \mathrm{H}, \mathrm{O}-\mathrm{CH}_{2}\right), 4.73$ and 4.52 (two d, $J=5.9 \mathrm{~Hz}, 1 \mathrm{H}, \mathrm{CH}), 3.87\left(\mathrm{~s}, 3 \mathrm{H}, \mathrm{O}-\mathrm{CH}_{3}\right), 3.26-3.19\left(\mathrm{~m}, 1 \mathrm{H}, \mathrm{CH}_{2}\right), 3.12-2.92\left(\mathrm{~m}, 1 \mathrm{H}, \mathrm{CH}_{2}\right), 2.74$ and 2.37 (two s, $3 \mathrm{H}, \mathrm{N}-\mathrm{CH}_{3}$ ), 1.41 and 1.33 (two s, 9H, C-CH ) $^{13}{ }^{13} \mathrm{CNR}\left(100 \mathrm{MHz}, \mathrm{CDCl}_{3}\right) \delta$ 176.3, 156.3, 155.1, 149.6, 146.9, 137.2, 130.6, 130.3, 128.5, 127.8, 127.3, 121.1, 121.0, 114.2, 112.7, 112.5, 80.7, 80.6, 71.1, 61.8, 60.3, 56.0, 34.8, 34.3, 32.8, 28.3, 28.2; HRMS (ESI) calcd. for $\mathrm{C}_{23} \mathrm{H}_{29} \mathrm{NNaO}_{6}{ }^{+}[\mathrm{M}+\mathrm{Na}]^{+}$ 438.1887, found 438.1880 .

For 3-(3-(benzyloxy)-4-methoxyphenyl)-2-((tert-butoxycarbonyl)(methyl)amino)propanoic acid (11b): Brown oil; Yield $76 \% ;{ }^{1} \mathrm{H} \mathrm{NMR} \mathrm{(400} \mathrm{MHz,} \mathrm{CDCl}_{3}$, exists as a complex mixture of two rotamers at room temperature) $\delta 7.44-7.27(\mathrm{~m}, 5 \mathrm{H}, \mathrm{Ar}-\mathrm{H}), 6.83-6.67(\mathrm{~m}, 3 \mathrm{H}, \mathrm{Ar}-\mathrm{H}), 5.11\left(\mathrm{~s}, 2 \mathrm{H}, \mathrm{O}-\mathrm{CH}_{2}\right), 4.72-4.66$ and 4.45-4.35 (two m, 1H, $\left.\mathrm{CHCH}_{2}\right), 3.84\left(\mathrm{~s}, 3 \mathrm{H}, \mathrm{O}_{-} \mathrm{CH}_{3}\right), 3.25-3.10\left(\mathrm{~m}, 1 \mathrm{H}, \mathrm{CHCH}_{2}\right), 3.04-2.84(\mathrm{~m}, 1 \mathrm{H}$, $\mathrm{CHCH}_{2}$ ), 2.64 and 2.57 (two s, $\left.3 \mathrm{H}, \mathrm{N}-\mathrm{CH}_{3}\right), 1.39$ and 1.33 (two s, $\left.9 \mathrm{H}, \mathrm{C}-\mathrm{CH}_{3}\right) ;{ }^{13} \mathrm{C} \mathrm{NMR}(100 \mathrm{MHz}$, $\left.\mathrm{CDCl}_{3}\right) \delta 176.4,156.4,155.0,148.6,148.5,148.0,137.2,137.1,130.0,129.6,127.9,127.4,127.4,121.8,121.7$, 115.1, 114.8, 112.1, 111.9, 80.7, 77.31, 71.2, 71.0, 61.8, 60.6, 60.5, 56.1, 34.8, 34.2, 33.0, 14.2; HRMS (ESI) calcd. for $\mathrm{C}_{23} \mathrm{H}_{29} \mathrm{NNaO}_{6}{ }^{+}[\mathrm{M}+\mathrm{Na}]^{+} 438.1887$, found 438.1883 .

For 3-(4-(benzyloxy)-3,5-dimethoxyphenyl)-2-((tert-butoxycarbonyl)(methyl)amino)propanoic acid (11c): Brown oil; Yield 79\%; ${ }^{1} \mathrm{H}$ NMR $\left(400 \mathrm{MHz}, \mathrm{CDCl}_{3}\right.$, exists as a complex mixture of two rotamers at room temperature) $\delta 7.47(\mathrm{~d}, J=7.0 \mathrm{~Hz}, 2 \mathrm{H}, \mathrm{Ar}-\mathrm{H}), 7.36-7.27(\mathrm{~m}, 3 \mathrm{H}, \mathrm{Ar}-\mathrm{H}), 6.42$ and $6.37(\mathrm{two} \mathrm{s}, 2 \mathrm{H}$, $\mathrm{Ar}-\mathrm{H}), 4.98$ (s, 2H, O-CH 2 ), 4.80-4.70 and 4.55-4.45 (two m, 1H, CH), $3.80\left(\mathrm{~s}, 6 \mathrm{H}, \mathrm{O}_{-} \mathrm{CH}_{3}\right), 3.33-3.17(\mathrm{~m}$, $1 \mathrm{H}, \mathrm{CH}_{2}$ ), 3.15-2.95 (m, $1 \mathrm{H}, \mathrm{CH}_{2}$ ), 2.73 and 2.67 (two s, 3H, N-CH 3 ), 1.43 and 1.36 (two s, 9H, C-CH ); $^{2}$ ${ }^{13} \mathrm{C}$ NMR $\left(100 \mathrm{MHz}, \mathrm{CDCl}_{3}\right) \delta 176.0,156.2,154.9,153.5,153.4,137.8,137.7,135.7,135.5,133.3,132.9$, $130.2,128.5,128.1,127.8,106.0,105.8,80.7,75.0,61.8,60.3,56.1,35.5,34.9,33.1,33.0,28.3,28.2$; HRMS (ESI) calcd. for $\mathrm{C}_{24} \mathrm{H}_{31} \mathrm{NNaO}_{7}^{+}[\mathrm{M}+\mathrm{Na}]^{+} 468.1993$, found 468.1989 .

For 3-(4-(benzyloxy)phenyl)-2-((tert-butoxycarbonyl)(methyl)amino)propanoic acid (11d): White powder; m.p.: $126-127{ }^{\circ} \mathrm{C}$ Yield $79 \% ;{ }^{1} \mathrm{H} \mathrm{NMR}\left(400 \mathrm{MHz}, \mathrm{CDCl}_{3}\right.$, exists as a 1:1 mixture of two rotamers) $\delta$ 7.47-7.29 (m, 5H, Ar-H), 7.14-7.08 (m, 2H, Ar-H), $6.91(\mathrm{~d}, J=8.0 \mathrm{~Hz}, 2 \mathrm{H}, \mathrm{Ar}-\mathrm{H}), 5.04(\mathrm{~s}, 2 \mathrm{H}$, O-CH $)_{2}, 4.71-4.66$ and 4.60-4.53 (two $\left.\mathrm{m}, 1 \mathrm{H}, \mathrm{CHCH}_{2}\right), 3.33-3.17\left(\mathrm{~m}, 1 \mathrm{H}, \mathrm{CHCH}_{2}\right), 3.16-2.92(\mathrm{~m}, 1 \mathrm{H}$, $\mathrm{CHCH}_{2}$ ), 2.75 and 2.67 (two s, 3H, N-CH 3 ), 1.41 and 1.35 (two s, 9H, C-CH ). $^{2}$. 
General procedure for the preparation of carbamates 12. The mixture of acids $\mathbf{1 1}$ $(0.75 \mathrm{~mol}), \mathrm{N}, \mathrm{N}$-diisopropylethylamine $(232.87 \mathrm{mmol}), 1$-hydroxybenzotriazole $(82.63 \mathrm{mmol})$, 1-ethyl-3-(3-dimethyllaminopropyl)carbodiimide hydrochloride (EDC. $\mathrm{HCl})(82.63 \mathrm{mmol})$ and $\mathrm{N}, \mathrm{O}$-dimethylhydroxylamine hydrochloride $(82.63 \mathrm{mmol})$ in dichloromethane $(200 \mathrm{~mL})$ was stirred at room temperature for $12 \mathrm{~h}$. Then, the reaction mixture was acidified to $\mathrm{pH} 5-6$ with dilute hydrochloric acid and filtered. The filtrate was extracted with dichloromethane $(100 \mathrm{~mL} \times 3)$. The combined organic layer was washed with brine $(100 \mathrm{~mL})$ and dried with $\mathrm{MgSO}_{4}$ anhydrous. The solution was filtered and evaporated under vacuum. The residue was purified by column chromatography on silica gel to give carbamates 12.

For tert-butyl (3-(4-(benzyloxy)-3-methoxyphenyl)-1-(methoxy(methyl)amino)-1-oxopropan-2-yl) (methyl)carbamate (12a): Yellow oil; Yield 73\%; ${ }^{1} \mathrm{H} \mathrm{NMR}\left(400 \mathrm{MHz}, \mathrm{CDCl}_{3}\right.$, exists as a complex mixture of two rotamers at room temperature) $\delta 7.45-7.28(\mathrm{~m}, 5 \mathrm{H}, \mathrm{Ar}-\mathrm{H}), 6.83-6.61(\mathrm{~m}, 3 \mathrm{H}, \mathrm{Ar}-\mathrm{H}), 5.52$ and 5.09 (two s, $1 \mathrm{H}, \mathrm{CH}), 5.12\left(\mathrm{~s}, 2 \mathrm{H}, \mathrm{O}-\mathrm{CH}_{2}\right), 3.87\left(\mathrm{~s}, 3 \mathrm{H}, \mathrm{O}-\mathrm{CH}_{3}\right), 3.62$ and 3.59 (two s, $3 \mathrm{H}, \mathrm{O}-\mathrm{CH}_{3}$ ), 3.18 and 3.15 (two s, $\left.3 \mathrm{H}, \mathrm{N}-\mathrm{CH}_{3}\right), 3.15-2.86\left(\mathrm{~m}, 2 \mathrm{H}, \mathrm{CH}_{2}\right), 2.84\left(\mathrm{~s}, 3 \mathrm{H}, \mathrm{N}-\mathrm{CH}_{3}\right), 1.37$ and 1.24 (two s, 9H, $\left.\mathrm{C}-\mathrm{CH}_{3}\right) ;{ }^{13} \mathrm{C} \mathrm{NMR}\left(100 \mathrm{MHz}, \mathrm{CDCl}_{3}\right) \delta 155.6,154.9,149.5,149.4,146.8,146.7,137.3,131.2,130.6,128.5$, 127.7, 127.2, 121.3, 114.2, 114.1, 113.1, 112.9, 79.7, 71.1, 61.3, 60.4, 57.3, 55.9, 54.4, 34.5, 32.3, 30.2, 29.9, 28.3, 28.1, 21.0, 14.2; HRMS (ESI) calcd. for $\mathrm{C}_{25} \mathrm{H}_{35} \mathrm{~N}_{2} \mathrm{O}_{6}{ }^{+}[\mathrm{M}+\mathrm{H}]^{+} 459.2490$, found 459.2498.

For tert-butyl (3-(3-(benzyloxy)-4-methoxyphenyl)-1-(methoxy(methyl)amino)-1-oxopropan-2-yl) (methyl)carbamate (12b): Yellow oil; Yield $80 \% ;{ }^{1} \mathrm{H} \mathrm{NMR}\left(400 \mathrm{MHz}, \mathrm{CDCl}_{3}\right.$, exists as a complex mixture of two rotamers at room temperature) $\delta 7.50-7.28(\mathrm{~m}, 5 \mathrm{H}, \mathrm{Ar}-\mathrm{H}), 6.87-6.70(\mathrm{~m}, 3 \mathrm{H}, \mathrm{Ar}-\mathrm{H})$, 5.49 and 5.06 (two s, $\left.1 \mathrm{H}, \mathrm{CHCH}_{2}\right), 5.12\left(\mathrm{~s}, 2 \mathrm{H}, \mathrm{O}-\mathrm{CH}_{2}\right), 3.85\left(\mathrm{~s}, 3 \mathrm{H}, \mathrm{O}-\mathrm{CH}_{3}\right), 3.62$ and 3.57 (two s, $3 \mathrm{H}$, $\mathrm{O}-\mathrm{CH}_{3}$ ), 3.17 and 3.14 (two s, $\left.3 \mathrm{H}, \mathrm{N}-\mathrm{CH}_{3}\right), 3.11-2.81\left(\mathrm{~m}, 2 \mathrm{H}, \mathrm{CHCH}_{2}\right.$ ), 2.79 and 2.78 (two s, $3 \mathrm{H}, \mathrm{N}-\mathrm{CH}_{3}$ ), 1.38 and 1.28 (two s, $\left.9 \mathrm{H}, \mathrm{C}-\mathrm{CH}_{3}\right) ;{ }^{13} \mathrm{C} \mathrm{NMR}\left(100 \mathrm{MHz}, \mathrm{CDCl}_{3}\right) \delta 155.7,155.0,148.5,148.3,148.2,148.0$, 137.3, 137.2, 130.6, 129.9, 128.6, 127.8, 127.4, 127.3, 122.1, 122.0, 115.4, 115.1, 112.1, 111.9, 79.8, 79.7, 77.3, 71.1, 71.0, 61.6, 61.3, 57.4, 56.2, 56.1, 54.5, 34.5, 32.4, 32.1, 30.2, 30.0, 28.3, 28.2; HRMS (ESI) calcd. for $\mathrm{C}_{25} \mathrm{H}_{35} \mathrm{~N}_{2} \mathrm{O}_{6}{ }^{+}[\mathrm{M}+\mathrm{H}]^{+} 459.2490$, found 459.2490 .

For tert-butyl (3-(4-(benzyloxy)-3,5-dimethoxyphenyl)-1-(methoxy(methyl)amino)-1-oxopropan-2-yl) (methyl)carbamate (12c): Brown oil; Yield 67\%; ${ }^{1} \mathrm{H}$ NMR $\left(400 \mathrm{MHz}, \mathrm{CDCl}_{3}\right) \delta 7.53-7.45(\mathrm{~m}, 2 \mathrm{H}, \mathrm{Ar}-\mathrm{H})$, 7.38-7.28 (m, 3H, Ar-H), 6.46 and 6.37 (two s, 2H, Ar-H), 5.57 and 5.12 (two s, $1 \mathrm{H}, \mathrm{CH}), 4.96(\mathrm{~s}, 2 \mathrm{H}$, $\left.\mathrm{O}-\mathrm{CH}_{2}\right), 3.80\left(\mathrm{~s}, 6 \mathrm{H}, \mathrm{O}-\mathrm{CH}_{3}\right), 3.63$ and 3.60 (two s, $\left.3 \mathrm{H}, \mathrm{O}-\mathrm{CH}_{3}\right), 3.20$ and 3.16 (two s, $3 \mathrm{H}, \mathrm{N}-\mathrm{CH}_{3}$ ), 3.14-3.07 (m, $\left.1 \mathrm{H}, \mathrm{CH}_{2}\right), 2.96-2.88\left(\mathrm{~m}, 1 \mathrm{H}, \mathrm{CH}_{2}\right), 2.85$ and 2.84 (two s, $\left.3 \mathrm{H}, \mathrm{N}-\mathrm{CH}_{3}\right), 1.39$ and 1.27 (two s, 9H, C-CH $\left.{ }_{3}\right) ;{ }^{13} \mathrm{C}$ NMR $\left(100 \mathrm{MHz}, \mathrm{CDCl}_{3}\right) \delta 155.6,154.9,153.4,153.2,137.9,137.8,135.6,135.4,134.0$, 133.1, 128.5, 128.1, 128.1, 127.8, 127.7, 106.3, 106.1, 79.8, 75.0, 75.0, 61.5, 61.3, 60.8, 60.4, 57.4, 56.1, 56.0, $53.9,35.3,32.3,32.0,30.2,30.0,28.3,28.15,21.0,14.2$; HRMS (ESI) calcd. for $\mathrm{C}_{26} \mathrm{H}_{37} \mathrm{~N}_{2} \mathrm{O}_{7}{ }^{+}[\mathrm{M}+\mathrm{H}]^{+}$ 489.2595 , found 489.2603 .

For tert-butyl (3-(4-(benzyloxy)phenyl)-1-(methoxy(methyl)amino)-1-oxopropan-2-yl)(methyl) carbamate (12d): Yellow oil; Yield $85 \%$; ${ }^{1} \mathrm{H}$ NMR $\left(400 \mathrm{MHz}, \mathrm{CDCl}_{3}\right.$, exists as a complex mixture of two rotamers at room temperature) $\delta 7.43-7.30(\mathrm{~m}, 5 \mathrm{H}, \mathrm{Ar}-\mathrm{H}), 7.16$ and 7.08 (two d, $J=8.2 \mathrm{~Hz}, 2 \mathrm{H}, \mathrm{Ar}-\mathrm{H}$ ), 6.93-6.85 (m, 2H, Ar-H), 5.50 and 5.12 (two s, $\left.1 \mathrm{H}, \mathrm{CHCH}_{2}\right), 5.03\left(\mathrm{~s}, 2 \mathrm{H}, \mathrm{O}_{-} \mathrm{CH}_{2}\right), 3.63$ and 3.60 (two s, $\left.3 \mathrm{H}, \mathrm{O}-\mathrm{CH}_{3}\right), 3.19$ and 3.16 (two s, 3H, N-CH $), 3.10-2.89\left(\mathrm{~m}, 2 \mathrm{H}, \mathrm{CHCH}_{2}\right), 2.84\left(\mathrm{~s}, 3 \mathrm{H}, \mathrm{N}-\mathrm{CH}_{3}\right), 1.36$ and 1.25 (two s, $9 \mathrm{H}, \mathrm{CCH}_{3}$ ).

General procedure for the preparation of carbamates 13. To the stirring mixture of magnesium ribbon $(22.50 \mathrm{mmol})$ in THF $(20 \mathrm{~mL})$ was added dropwise the solution of 4- methoxy benzyl chloride $(13.58 \mathrm{mmol})$ in THF $(10 \mathrm{~mL})$ and absolute ether $(5 \mathrm{~mL})$ at $0{ }^{\circ} \mathrm{C}$ under argon atmosphere. The mixture was stirred at room temperature for $1 \mathrm{~h}$. Then, to the reaction mixture was added the solution of $12(6.79 \mathrm{mmol})$ in THF $(50 \mathrm{~mL})$ at $0{ }^{\circ} \mathrm{C}$. The mixture was stirred at room temperature for $3 \mathrm{~h}$. Then, saturated ammonium chloride solution $(30 \mathrm{~mL})$ and $\mathrm{H}_{2} \mathrm{O}(20 \mathrm{~mL})$ were added. The reaction solution was extracted with absolute ether $(50 \mathrm{~mL} \times 3)$. The combined organic layer was washed with brine 
$(100 \mathrm{~mL})$ and dried with $\mathrm{MgSO}_{4}$ anhydrous. The solution was filtered and evaporated under vacuum. The residue was purified by column chromatography on silica gel to give carbamates 13 .

For tert-butyl (1-(4-(benzyloxy)-3-methoxyphenyl)-4-(4-methoxyphenyl)-3-oxobutan-2-yl)(methyl) carbamate (13a): Yellow oil; Yield $85 \% ;{ }^{1} \mathrm{H}$ NMR $\left(400 \mathrm{MHz}, \mathrm{CDCl}_{3}\right.$, exists as a complex mixture of two rotamers at room temperature) $\delta 7.45-7.28(\mathrm{~m}, 5 \mathrm{H}, \mathrm{Ar}-\mathrm{H}), 7.12-7.04(\mathrm{~m}, 2 \mathrm{H}, \mathrm{Ar}-\mathrm{H}), 6.88-6.80$ $(\mathrm{m}, 2 \mathrm{H}, \mathrm{Ar}-\mathrm{H}), 6.77-6.74(\mathrm{~m}, 1 \mathrm{H}, \mathrm{Ar}-\mathrm{H}), 6.68-6.52(\mathrm{~m}, 2 \mathrm{H}, \mathrm{Ar}-\mathrm{H}), 5.11\left(\mathrm{~s}, 2 \mathrm{H}, \mathrm{O}-\mathrm{CH}_{2}\right), 4.78-4.70$ and 4.30-4.20 (two $\mathrm{m}, 1 \mathrm{H}, \mathrm{CH}$ ), $3.83\left(\mathrm{~s}, 3 \mathrm{H}, \mathrm{O}-\mathrm{CH}_{3}\right), 3.79$ and 3.78 (two s, $\left.3 \mathrm{H}, \mathrm{O}-\mathrm{CH}_{3}\right), 3.74-3.61(\mathrm{~m}, 2 \mathrm{H}$, C- $\left.\mathrm{CH}_{2}\right), 3.19-3.01\left(\mathrm{~m}, 1 \mathrm{H}, \mathrm{CH}_{2}\right), 2.85-2.76\left(\mathrm{~m}, 1 \mathrm{H}, \mathrm{CH}_{2}\right), 2.58$ and 2.51 (two s, 3H, N-CH $\left.\mathrm{CH}_{3}\right), 1.43$ and 1.34 (two s, 9H, C-CH $\left.{ }_{3}\right) ;{ }^{13} \mathrm{C}$ NMR $\left(100 \mathrm{MHz} \mathrm{CDCl}_{3}\right) \delta 206.0,205.9,158.7,158.6,155.8,154.9,149.6$, $149.5,146.8,146.6,137.3,137.2,131.2,130.8,130.5,130.5,128.5,127.8,127.3,127.3,125.8,125.7,121.2$, $121.1,114.3,114.2,114.1,114.0,112.8,112.7,80.8,80.3,71.1,66.8,65.9,64.4,56.0,55.9,55.3,55.2,46.2$, 45.7, 33.4, 32.9, 32.3, 28.4, 28.2; HRMS (ESI) calcd. for $\mathrm{C}_{31} \mathrm{H}_{37} \mathrm{NNaO}_{6}{ }^{+}[\mathrm{M}+\mathrm{Na}]^{+} 542.2513$, found 542.2515 .

For tert-butyl (1-(3-(benzyloxy)-4-methoxyphenyl)-4-(4-methoxyphenyl)-3-oxobutan-2-yl)(methyl) carbamate (13b): Yellow oil; Yield 91\%; ${ }^{1} \mathrm{H}$ NMR $\left(400 \mathrm{MHz}, \mathrm{CDCl}_{3}\right.$, exists as a complex mixture of two rotamers at room temperature) $\delta 7.48-7.27(\mathrm{~m}, 5 \mathrm{H}, \mathrm{Ar}-\mathrm{H}), 7.07(\mathrm{dd}, J=8.5,3.1 \mathrm{~Hz}, 2 \mathrm{H}, \mathrm{Ar}-\mathrm{H})$, 6.91-6.73 (m, 3H, Ar-H), 6.71-6.58 (m, 2H, Ar-H), 5.15-5.01 (m, 2H, O- $\left.\mathrm{CH}_{2}\right), 4.70-4.60$ and 4.19-4.09 (two $\left.\mathrm{m}, 1 \mathrm{H}, \mathrm{CHCH}_{2}\right), 3.84\left(\mathrm{~s}, 3 \mathrm{H}, \mathrm{O}-\mathrm{CH}_{3}\right), 3.79-3.76\left(\mathrm{~m}, 3 \mathrm{H}, \mathrm{O}-\mathrm{CH}_{3}\right), 3.73-3.58\left(\mathrm{~m}, 2 \mathrm{H}, \mathrm{CO}-\mathrm{CH}_{2}\right)$, 3.14-3.00 (m, 1H, $\left.\mathrm{CHCH}_{2}\right), 2.83-2.70\left(\mathrm{~m}, 1 \mathrm{H}, \mathrm{CHCH}_{2}\right), 2.48$ and $2.43\left(\mathrm{two} \mathrm{s}, 3 \mathrm{H}, \mathrm{N}-\mathrm{CH}_{3}\right), 1.44$ and 1.36 (two s, 9H, C-CH $\left.)_{3}\right){ }^{13} \mathrm{C}$ NMR $\left(100 \mathrm{MHz}, \mathrm{CDCl}_{3}\right) \delta 205.9,158.7,154.8,148.5,148.1,137.1,130.5,130.5$, $130.1,128.6,127.8,127.4,127.3,125.8,125.7,121.9,115.2,115.0,114.2,114.0,112.0,111.9,80.9,80.3,71.0$, $70.9,67.0,64.5,56.1,55.3,46.2,45.7,33.4,32.8,32.3,28.4,28.3$; HRMS (ESI) calcd. for $\mathrm{C}_{31} \mathrm{H}_{37} \mathrm{NNaO}_{6}{ }^{+}$ $[\mathrm{M}+\mathrm{Na}]^{+} 542.2513$, found 542.2517 .

For tert-butyl (1-(4-(benzyloxy)-3,5-dimethoxyphenyl)-4-(4-methoxyphenyl)-3-oxobutan-2-yl)(methyl) carbamate (13c): Yellow oil; Yield 85\%; ${ }^{1} \mathrm{H}$ NMR $\left(400 \mathrm{MHz}, \mathrm{CDCl}_{3}\right) \delta 7.46(\mathrm{~d}, J=7.4 \mathrm{~Hz}, 2 \mathrm{H}, \mathrm{Ar}-\mathrm{H})$, 7.35-7.26 (m, 3H, Ar-H), 7.16-7.05 (m, 2H, Ar-H), 6.92-6.81 (m, 2H, Ar-H), 6.33 and 6.26 (two s, 2H, Ar-H), 4.96 (s, 2H, O-CH CH $_{2}, 4.76-4.70$ and $4.25-4.15$ (two $\mathrm{m}, 1 \mathrm{H}, \mathrm{CH}$ ), 3.79 and 3.78 (two s, $3 \mathrm{H}, \mathrm{O}-\mathrm{CH}_{3}$ ), $3.76\left(\mathrm{~s}, 6 \mathrm{H}, \mathrm{O}-\mathrm{CH}_{3}\right), 3.74-3.61\left(\mathrm{~m}, 2 \mathrm{H}, \mathrm{CO}-\mathrm{CH}_{2}\right), 3.17-3.05\left(\mathrm{~m}, 1 \mathrm{H}, \mathrm{CHCH}_{2}\right), 2.89-2.72\left(\mathrm{~m}, 1 \mathrm{H}, \mathrm{CHCH}_{2}\right)$, 2.56 and 2.51 (two s, $\left.3 \mathrm{H}, \mathrm{N}-\mathrm{CH}_{3}\right), 1.46$ and 1.37 (two s, 9H, C- $\left.\mathrm{CH}_{3}\right) ;{ }^{13} \mathrm{C} \mathrm{NMR}\left(100 \mathrm{MHz}, \mathrm{CDCl}_{3}\right.$ ) $\delta$ 205.9, 205.8, 158.8, 158.6, 155.8, 154.8, 153.6, 153.4, 138.0, 137.8, 135.5, 135.4, 134.0, 133.5, 130.6, 130.5, 128.6, 128.6, 128.2, 127.9, 127.8, 125.8, 125.7, 114.2, 114.1, 113.9, 113.6, 106.1, 106.1, 80.9, 80.4, 75.0, 67.0, 64.9, 64.3, 56.2, 56.1, 56.0, 55.3, 55.3, 55.2, 46.2, 45.7, 34.2, 33.7, 28.4, 28.3; HRMS (ESI) calcd. for $\mathrm{C}_{32} \mathrm{H}_{39} \mathrm{NNaO}_{7}^{+}[\mathrm{M}+\mathrm{Na}]^{+}$572.2619, found 572.2614.

For tert-butyl (1-(4-(benzyloxy)phenyl)-4-(4-methoxyphenyl)-3-oxobutan-2-yl)(methyl)carbamate (13d): Light liquid; Yield $92 \% ;{ }^{1} \mathrm{H}$ NMR $\left(400 \mathrm{MHz}, \mathrm{CDCl}_{3}\right.$, exists as a 1:1 mixture of two rotamers) 反 7.45-7.27 (m, 5H, Ar-H), 7.10-6.98 (m, 4H, Ar-H), 6.89-6.79 (m, 4H, Ar-H), 5.02 (s, 2H, O-CH $)_{2}$, 4.76-4.70 and 4.35-4.25 (two $\mathrm{m}, 1 \mathrm{H}, \mathrm{CH}), 3.78$ and 3.79 (two s, 3H, O-CH $\left.{ }_{3}\right), 3.73-3.61\left(\mathrm{~m}, 2 \mathrm{H}, \mathrm{CH}_{2} \mathrm{CO}\right.$ ), 3.15-3.07 (m, 1H, $\left.\mathrm{CHCH}_{2}\right), 2.87-2.75\left(\mathrm{~m}, 1 \mathrm{H}, \mathrm{CHCH}_{2}\right), 2.58$ and $2.52\left(\right.$ two s, $\left.3 \mathrm{H}, \mathrm{N}-\mathrm{CH}_{3}\right), 1.43$ and 1.34 (two s, 9H, $\mathrm{CCH}_{3}$ ).

General procedure for the preparation of amines 15. To the solution of absolute ether $(11.4 \mathrm{~mL})$ and ethanol $(8.7 \mathrm{~mL})$ was added dropwise acetyl chloride $(7.9 \mathrm{~mL})$ at $-30{ }^{\circ} \mathrm{C}$, and stirred at room temperature for $10 \mathrm{~min}$. Then, carbamates $13(1.43 \mathrm{mmol})$ was added. The reaction solution was stirred at room temperature for $1 \mathrm{~h}$ and concentrated. Then, absolute ether $(20 \mathrm{~mL})$ was added. The mixture was filtrated to give hydrochlorides 14 , which was used for the next step directly. The mixture of hydrochlorides 14 and $\mathrm{NH}_{2} \mathrm{CN}(1.32 \mathrm{mmol})$ in $\mathrm{H}_{2} \mathrm{O}(30 \mathrm{~mL})$ was stirred at $90{ }^{\circ} \mathrm{C}$ for $1 \mathrm{~h}$, cooled to room temperature, filtrated to give amines 15 .

For 5-(4-(benzyloxy)-3-methoxybenzyl)-4-(4-methoxybenzyl)-1-methyl-1H-imidazol-2-amine (15a): Brown powder; Yield 73\%; m.p.: $95{ }^{\circ} \mathrm{C}$ (dec.); ${ }^{1} \mathrm{H}$ NMR $\left(400 \mathrm{MHz}, \mathrm{CDCl}_{3}\right) \delta$ 7.44-7.29 (m, 5H, Ar-H), 
$7.18(\mathrm{~d}, J=8.4 \mathrm{~Hz}, 2 \mathrm{H}, \mathrm{Ar}-\mathrm{H}), 6.79-6.76(\mathrm{~m}, 3 \mathrm{H}, \mathrm{Ar}-\mathrm{H}), 6.55-6.48(\mathrm{~m}, 2 \mathrm{H}, \mathrm{Ar}-\mathrm{H}), 5.64\left(\mathrm{~s}, 2 \mathrm{H}, \mathrm{NH}_{2}\right), 5.12$ (s, 2H, O-CH $\left.\mathrm{CH}_{2}\right), 3.80\left(\mathrm{~s}, 2 \mathrm{H}, \mathrm{CH}_{2}\right), 3.77\left(\mathrm{~s}, 2 \mathrm{H}, \mathrm{CH}_{2}\right), 3.75\left(\mathrm{~s}, 3 \mathrm{H}, \mathrm{O}-\mathrm{CH}_{3}\right), 3.71\left(\mathrm{~s}, 3 \mathrm{H}, \mathrm{O}-\mathrm{CH}_{3}\right), 3.08(\mathrm{~s}$, $\left.3 \mathrm{H}, \mathrm{N}-\mathrm{CH}_{3}\right) ;{ }^{13} \mathrm{C} \mathrm{NMR}\left(100 \mathrm{MHz}, \mathrm{CDCl}_{3}\right) \delta 157.8,149.9,147.0,146.8,137.2,132.9,132.1,131.8,129.4$, 128.5, 127.8, 127.3, 120.8, 119.8, 114.1, 113.8, 111.6, 71.1, 55.9, 55.2, 32.1, 29.2, 29.1; HRMS (ESI) calcd. for $\mathrm{C}_{27} \mathrm{H}_{30} \mathrm{~N}_{3} \mathrm{O}_{3}{ }^{+}[\mathrm{M}+\mathrm{H}]^{+} 444.2282$, found 444.2289.

For 5-(3-(benzyloxy)-4-methoxybenzyl)-4-(4-methoxybenzyl)-1-methyl-1H-imidazol-2-amine (15b): Brown powder; Yield 88\%; m.p.: 56-58 ${ }^{\circ} \mathrm{C} ;{ }^{1} \mathrm{H}$ NMR $\left(400 \mathrm{MHz}, \mathrm{CDCl}_{3}\right) \delta$ 7.35-7.24 (m, 5H, Ar-H), 7.19 $(\mathrm{d}, J=8.4 \mathrm{~Hz}, 2 \mathrm{H}, \mathrm{Ar}-\mathrm{H}), 6.85-6.75$ (m, 3H, Ar-H), $6.64(\mathrm{~d}, J=7.8 \mathrm{~Hz}, 1 \mathrm{H}, \mathrm{Ar}-\mathrm{H}), 6.40$ (s, 1H, Ar-H), 5.11 (brs, $\left.2 \mathrm{H}, \mathrm{NH}_{2}\right), 4.93\left(\mathrm{~s}, 2 \mathrm{H}, \mathrm{O}-\mathrm{CH}_{2}\right), 3.86\left(\mathrm{~s}, 3 \mathrm{H}, \mathrm{O}-\mathrm{CH}_{3}\right), 3.74\left(\mathrm{~s}, 2 \mathrm{H}, \mathrm{CH}_{2}\right), 3.73\left(\mathrm{~s}, 2 \mathrm{H}, \mathrm{CH}_{2}\right), 3.71$ (s, $\left.3 \mathrm{H}, \mathrm{O}-\mathrm{CH}_{3}\right), 2.87\left(\mathrm{~s}, 3 \mathrm{H}, \mathrm{N}-\mathrm{CH}_{3}\right) ;{ }^{13} \mathrm{C} \mathrm{NMR}\left(100 \mathrm{MHz}, \mathrm{CDCl}_{3}\right) \delta 158.0,148.3,148.1,146.9,137.1,132.8$, 131.6, 130. 9, 129.6, 129.6, 128.6, 127.8, 127.4, 120.8, 120.4, 113.9, 111.9, 70.6, 56.1, 55.2, 32.0, 29.1, 28.9; HRMS (ESI) calcd. for $\mathrm{C}_{27} \mathrm{H}_{30} \mathrm{~N}_{3} \mathrm{O}_{3}{ }^{+}[\mathrm{M}+\mathrm{H}]^{+} 444.2282$, found 444.2291 .

For 5-(4-(benzyloxy)-3,5-dimethoxybenzyl)-4-(4-methoxybenzyl)-1-methyl-1H-imidazol-2-amine (15c): Brown powder; Yield 77\%; m.p.: 90-93 ${ }^{\circ} \mathrm{C} ;{ }^{1} \mathrm{H}$ NMR $\left(400 \mathrm{MHz}, \mathrm{CDCl}_{3}\right) \delta 7.46(\mathrm{~d}, J=7.0 \mathrm{~Hz}, 2 \mathrm{H}, \mathrm{Ar}-\mathrm{H})$, 7.36-7.27 (m, 3H, Ar-H), 7.19 (d, J = 8.3 Hz, 2H, Ar-H), 6.78 (d, J = 8.3 Hz, 2H, Ar-H), $6.22(\mathrm{~s}, 2 \mathrm{H}, \mathrm{Ar}-\mathrm{H})$, 4.96 (s, 2H, O-CH $)_{2}, 4.69$ (brs, $\left.2 \mathrm{H}, \mathrm{NH}_{2}\right), 3.81\left(\mathrm{~s}, 2 \mathrm{H}, \mathrm{CH}_{2}\right), 3.76\left(\mathrm{~s}, 2 \mathrm{H}, \mathrm{CH}_{2}\right), 3.75\left(\mathrm{~s}, 3 \mathrm{H}, \mathrm{O}-\mathrm{CH}_{3}\right), 3.67$

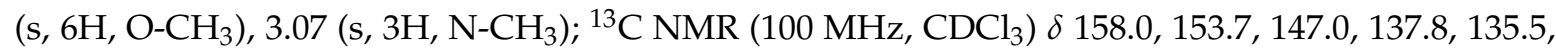
$134.2,132.5,129.5,128.5,128.1,127.8,120.6,113.9,104.9,75.0,56.1,55.3,31.9,29.8,29.3$; HRMS (ESI) calcd. for $\mathrm{C}_{28} \mathrm{H}_{32} \mathrm{~N}_{3} \mathrm{O}_{4}{ }^{+}[\mathrm{M}+\mathrm{H}]^{+} 474.2387$, found 474.2389 .

For 5-(4-(benzyloxy)benzyl)-4-(4-methoxybenzyl)-1-methyl-1H-imidazol-2-amine (15d): Brown powder; Yield 70\%; m.p.: $120-123{ }^{\circ} \mathrm{C} ;{ }^{1} \mathrm{H}$ NMR $\left(400 \mathrm{MHz}, \mathrm{CDCl}_{3}\right) \delta 7.43-7.30(\mathrm{~m}, 5 \mathrm{H}, \mathrm{Ar}-\mathrm{H}), 7.16(\mathrm{~d}$, $J=8.3 \mathrm{~Hz}, 2 \mathrm{H}, \mathrm{Ar}-\mathrm{H}), 6.98(\mathrm{~d}, J=8.3 \mathrm{~Hz}, 2 \mathrm{H}, \mathrm{Ar}-\mathrm{H}), 6.87(\mathrm{~d}, J=8.4 \mathrm{~Hz}, 2 \mathrm{H}, \mathrm{Ar}-\mathrm{H}), 6.79(\mathrm{~d}, J=8.4 \mathrm{~Hz}$, $2 \mathrm{H}, \mathrm{Ar}-\mathrm{H}), 5.03\left(\mathrm{~s}, 2 \mathrm{H}, \mathrm{O}-\mathrm{CH}_{2}\right), 3.85\left(\mathrm{~s}, 2 \mathrm{H}, \mathrm{NH}_{2}\right), 3.81\left(\mathrm{~s}, 2 \mathrm{H}, \mathrm{CH}_{2}\right), 3.75\left(\mathrm{~s}, 3 \mathrm{H}, \mathrm{O}_{-} \mathrm{CH}_{3}\right), 3.74(\mathrm{~s}, 2 \mathrm{H}$, $\mathrm{CH}_{2}$ ), 3.07 (s, 3H, N-CH 3 ); HRMS (ESI) calcd. for $\mathrm{C}_{26} \mathrm{H}_{28} \mathrm{~N}_{3} \mathrm{O}_{2}{ }^{+}[\mathrm{M}+\mathrm{H}]^{+}$414.2176, found 414.2179.

General procedure for the preparation of naamines 1a-d. The mixture of amines 15 (10.45 mmol), $\mathrm{Pd} / \mathrm{C}(10 \mathrm{wt} \%)(0.56 \mathrm{~g})$, methanol $(400 \mathrm{~mL})$ and acetic acid $(4 \mathrm{~mL})$ was bubbled with hydrogen and stirred at room temperature for $24 \mathrm{~h}$. Then, the mixture was filtered and concentrated. Then acetone $(15 \mathrm{~mL})$ was added, and filtered to give naamines 1 .

For naamine F (1a): Brick red powder; Yield 95\%; m.p.: 163-165 ${ }^{\circ} \mathrm{C} ;{ }^{1} \mathrm{H}$ NMR $\left(400 \mathrm{MHz}, \mathrm{CD}_{3} \mathrm{OD}\right) \delta$ $7.14(\mathrm{~d}, J=8.5 \mathrm{~Hz}, 2 \mathrm{H}, \mathrm{Ar}-\mathrm{H}), 6.77(\mathrm{~d}, J=8.5 \mathrm{~Hz}, 2 \mathrm{H}, \mathrm{Ar}-\mathrm{H}), 6.66(\mathrm{~d}, J=8.0 \mathrm{~Hz}, 1 \mathrm{H}, \mathrm{Ar}-\mathrm{H}), 6.53(\mathrm{dd}$, $J=8.0,1.4 \mathrm{~Hz}, 1 \mathrm{H}, \mathrm{Ar}-\mathrm{H}), 6.45(\mathrm{~d}, J=1.4 \mathrm{~Hz}, 1 \mathrm{H}, \mathrm{Ar}-\mathrm{H}), 3.80\left(\mathrm{~s}, 2 \mathrm{H}, \mathrm{CH}_{2}\right), 3.73\left(\mathrm{~s}, 3 \mathrm{H}, \mathrm{O}-\mathrm{CH}_{3}\right), 3.72(\mathrm{~s}$, $\left.2 \mathrm{H}, \mathrm{CH}_{2}\right), 3.58$ (s, 3H, O-CH 3 ), 3.09 (s, 3H, N-CH $\left.)_{3}\right) ;{ }^{13} \mathrm{C}$ NMR $\left(100 \mathrm{MHz}, \mathrm{CD}_{3} \mathrm{OD}\right) \delta 159.4,149.7,149.2$, $146.1,134.7,132.7,131.8,130.5,122.6,121.6,116.1,114.7,112.6,56.2,55.7,32.8,29.7,29.5$; HRMS (ESI) calcd. for $\mathrm{C}_{20} \mathrm{H}_{24} \mathrm{~N}_{3} \mathrm{O}_{3}{ }^{+}[\mathrm{M}+\mathrm{H}]^{+}$354.1812, found 354.1818.

For 1b: Brown powder; Yield 96\%; m.p.: 80-83 ${ }^{\circ} \mathrm{C} ;{ }^{1} \mathrm{H}$ NMR $\left(400 \mathrm{MHz}, \mathrm{CD}_{3} \mathrm{OD}\right) \delta 7.13(\mathrm{~d}, J=8.5 \mathrm{~Hz}$, $2 \mathrm{H}, \mathrm{Ar}-\mathrm{H}), 6.88-6.83(\mathrm{~m}, 3 \mathrm{H}, \mathrm{Ar}-\mathrm{H}), 6.61-6.58(\mathrm{~m}, 2 \mathrm{H}, \mathrm{Ar}-\mathrm{H}), 3.88\left(\mathrm{~s}, 2 \mathrm{H}, \mathrm{CH}_{2}\right), 3.84\left(\mathrm{~s}, 2 \mathrm{H}, \mathrm{CH}_{2}\right), 3.82$ $\left(\mathrm{s}, 3 \mathrm{H}, \mathrm{O}-\mathrm{CH}_{3}\right), 3.75\left(\mathrm{~s}, 3 \mathrm{H}, \mathrm{O}-\mathrm{CH}_{3}\right), 3.20\left(\mathrm{~s}, 3 \mathrm{H}, \mathrm{N}-\mathrm{CH}_{3}\right) ;{ }^{13} \mathrm{C} \mathrm{NMR}\left(100 \mathrm{MHz}, \mathrm{CD}_{3} \mathrm{OD}\right) \delta 160.2,148.2$, 148.1, 147.8, 130.8, 130.8, 130.6, 124.0, 123.8, 120.3, 116.1, 115.3, 113.1, 56.5, 55.8, 30.1, 29.8, 28.5; HRMS (ESI) calcd. for $\mathrm{C}_{20} \mathrm{H}_{24} \mathrm{~N}_{3} \mathrm{O}_{3}{ }^{+}[\mathrm{M}+\mathrm{H}]^{+}$354.1812, found 354.1818.

For naamine G (1c): Brick red powder; Yield 97\%; m.p.: $172-174{ }^{\circ} \mathrm{C} ;{ }^{1} \mathrm{H}$ NMR $\left(400 \mathrm{MHz}, \mathrm{CD}_{3} \mathrm{OD}\right) \delta$ $7.05(\mathrm{~d}, J=8.3 \mathrm{~Hz}, 2 \mathrm{H}, \mathrm{Ar}-\mathrm{H}), 6.67(\mathrm{~d}, J=8.3 \mathrm{~Hz}, 2 \mathrm{H}, \mathrm{Ar}-\mathrm{H}), 6.16(\mathrm{~s}, 2 \mathrm{H}, \mathrm{Ar}-\mathrm{H}), 3.71\left(\mathrm{~s}, 2 \mathrm{H}, \mathrm{CH}_{2}\right), 3.62(\mathrm{~s}$, $5 \mathrm{H}, \mathrm{CH}_{2}$ and $\left.\mathrm{O}-\mathrm{CH}_{3}\right), 3.54\left(\mathrm{~s}, 6 \mathrm{H}, \mathrm{O}-\mathrm{CH}_{3}\right), 3.01\left(\mathrm{~s}, 3 \mathrm{H}, \mathrm{N}-\mathrm{CH}_{3}\right) ;{ }^{13} \mathrm{C} \mathrm{NMR}\left(100 \mathrm{MHz}, \mathrm{CD}_{3} \mathrm{OD}\right) \delta 159.4$, 149.7, 149.3, 134.9, 134.7, 132.8, 131.1, 130.5, 122.4, 114.7, 106.2, 56.6, 55.7, 32.8, 30.1, 29.5; HRMS (ESI) calcd. for $\mathrm{C}_{21} \mathrm{H}_{26} \mathrm{~N}_{3} \mathrm{O}_{4}{ }^{+}[\mathrm{M}+\mathrm{H}]^{+} 384.1918$, found 384.1919.

For naamine A (1d): Grey powder; Yield 87\%; m.p.: 202-205 ${ }^{\circ} \mathrm{C} ;{ }^{1} \mathrm{H}$ NMR (400 MHz, $\left.\mathrm{CD}_{3} \mathrm{OD}\right) \delta 7.09$ $(\mathrm{d}, J=8.6 \mathrm{~Hz}, 2 \mathrm{H}, \mathrm{Ar}-\mathrm{H}), 6.85(\mathrm{~d}, J=8.4 \mathrm{~Hz}, 2 \mathrm{H}, \mathrm{Ar}-\mathrm{H}), 6.77(\mathrm{~d}, J=8.6 \mathrm{~Hz}, 2 \mathrm{H}, \mathrm{Ar}-\mathrm{H}), 6.65(\mathrm{~d}, J=8.4$ $\left.\mathrm{Hz}, 2 \mathrm{H}, \mathrm{Ar}-\mathrm{H}), 3.78\left(\mathrm{~s}, 2 \mathrm{H}, \mathrm{CH}_{2}\right), 3.73\left(\mathrm{~s}, 3 \mathrm{H}, \mathrm{O}-\mathrm{CH}_{3}\right), 3.71\left(\mathrm{~s}, 2 \mathrm{H}, \mathrm{CH}_{2}\right), 3.09\left(\mathrm{~s}, 3 \mathrm{H}, \mathrm{N}^{-C_{3}}\right)_{3}\right){ }^{13} \mathrm{C} \mathrm{NMR}$ 
(100 MHz, $\left.\mathrm{CD}_{3} \mathrm{OD}\right) \delta 160.0,157.5,148.4,131.5,130.5,130.2,129.0,125.2,123.8,116.6,115.1,55.7,30.2$, 29.8, 28.5; HRMS (ESI) calcd. for $\mathrm{C}_{19} \mathrm{H}_{22} \mathrm{~N}_{3} \mathrm{O}_{2}{ }^{+}[\mathrm{M}+\mathrm{H}]^{+}$324.1707, found 324.1707.

Synthesis of 1-methylimidazolidine-2,4,5-trione (16). The mixture of $\mathrm{N}$-monomethylurea (2.96 $\mathrm{g}$, $0.04 \mathrm{~mol}),(\mathrm{COCl})_{2}(3.3 \mathrm{~mL}, 0.04 \mathrm{~mol})$ in absolute ether $(100 \mathrm{~mL})$ was refluxed under argon for $2 \mathrm{~h}$ and concentrated. Then, dichloromethane $(10 \mathrm{~mL})$ was added, filtered to give $\mathbf{1 6}(2.87 \mathrm{~g}, 59 \%)$ as a white powder. m.p.: $146-149^{\circ} \mathrm{C},{ }^{1} \mathrm{H}$ NMR $\left(400 \mathrm{MHz}, \mathrm{DMSO}-d_{6}\right) \delta 11.99(\mathrm{~s}, 1 \mathrm{H}, \mathrm{NH}), 2.92\left(\mathrm{~s}, 3 \mathrm{H}, \mathrm{N}-\mathrm{CH}_{3}\right)$.

General procedure for the preparation of naamidines $2 \mathrm{a}-\mathbf{d}$. The solution of $\mathbf{1 6}(1.28 \mathrm{~g}, 10 \mathrm{mmol})$ and $\mathrm{N}, \mathrm{O}$-bis(trimethylsilyl)acetamide $(2.52 \mathrm{~g}, 12.4 \mathrm{mmol})$ in acetonitrile was refluxed under argon for $45 \mathrm{~min}$ and concentrated to give $\mathbf{1 7}$. The mixture of naamines $\mathbf{1}(2 \mathrm{mmol})$ and 17 in toluene $(16 \mathrm{~mL})$ was refluxed for $18 \mathrm{~h}$. The mixture was diluted with ethyl acetate $(180 \mathrm{~mL})$, washed with dilute hydrochloric acid $(100 \mathrm{~mL}), \mathrm{H}_{2} \mathrm{O}(100 \mathrm{~mL})$, brine $(100 \mathrm{~mL})$, dried with $\mathrm{MgSO}_{4}$ anhydrous, and evaporated under vacuum. The residue was purified by column chromatography on silica gel to give naamidines 2 .

For 2a: Yellow powder; Yield 54\%; m.p.: $162-164{ }^{\circ} \mathrm{C} ;{ }^{1} \mathrm{H}$ NMR $\left(400 \mathrm{MHz}, \mathrm{CDCl}_{3}\right) \delta 7.14(\mathrm{~d}, J=8.6 \mathrm{~Hz}$, 2H, Ar-H), 6.84-6.77 (m, 3H, Ar-H), $6.54(\mathrm{dd}, J=8.1,1.8 \mathrm{~Hz}, 1 \mathrm{H}, \mathrm{Ar}-\mathrm{H}), 6.34(\mathrm{~d}, J=1.8 \mathrm{~Hz}, 1 \mathrm{H}, \mathrm{Ar}-\mathrm{H})$, $3.90\left(\mathrm{~s}, 4 \mathrm{H}, \mathrm{CH}_{2}\right), 3.77\left(\mathrm{~s}, 3 \mathrm{H}, \mathrm{O}-\mathrm{CH}_{3}\right), 3.65\left(\mathrm{~s}, 3 \mathrm{H}, \mathrm{O}-\mathrm{CH}_{3}\right), 3.49\left(\mathrm{~s}, 3 \mathrm{H}, \mathrm{N}-\mathrm{CH}_{3}\right), 3.18\left(\mathrm{~s}, 3 \mathrm{H}, \mathrm{N}_{-} \mathrm{CH}_{3}\right)$; ${ }^{13} \mathrm{C}$ NMR $\left(100 \mathrm{MHz}, \mathrm{CDCl}_{3}\right) \delta 162.2,158.2,155.4,146.8,146.4,144.6,144.5,135.8,131.6,129.3,128.8$, 126.9, 120.7, 114.5, 114.0, 110.2, 55.8, 55.3, 32.2, 30.0, 29.2, 24.7; HRMS (ESI) calcd. for $\mathrm{C}_{24} \mathrm{H}_{26} \mathrm{~N}_{5} \mathrm{O}_{5}{ }^{+}$ $[\mathrm{M}+\mathrm{H}]^{+} 464.1928$, found 464.1932 .

For naamidine B (2b): Yellow powder; Yield 37\%; m.p.: 157-159 ${ }^{\circ} \mathrm{C} ;{ }^{1} \mathrm{H}$ NMR $\left(400 \mathrm{MHz}, \mathrm{CDCl}_{3}\right) \delta 7.12$ $(\mathrm{d}, J=8.5 \mathrm{~Hz}, 2 \mathrm{H}, \mathrm{Ar}-\mathrm{H}), 6.82(\mathrm{~d}, J=8.5 \mathrm{~Hz}, 2 \mathrm{H}, \mathrm{Ar}-\mathrm{H}), 6.72(\mathrm{~d}, J=8.1 \mathrm{~Hz}, 1 \mathrm{H}, \mathrm{Ar}-\mathrm{H}), 6.58(\mathrm{~s}, 1 \mathrm{H}, \mathrm{Ar}-\mathrm{H})$, $6.46(\mathrm{~d}, J=8.1 \mathrm{~Hz}, 1 \mathrm{H}, \mathrm{Ar}-\mathrm{H}), 3.89\left(\mathrm{~s}, 2 \mathrm{H}, \mathrm{CH}_{2}\right), 3.86\left(\mathrm{~s}, 5 \mathrm{H}, \mathrm{CH}_{2}\right.$ and $\left.\mathrm{O}_{-} \mathrm{CH}_{3}\right), 3.78\left(\mathrm{~s}, 3 \mathrm{H}, \mathrm{O}-\mathrm{CH}_{3}\right), 3.49$ $\left(\mathrm{s}, 3 \mathrm{H}, \mathrm{N}-\mathrm{CH}_{3}\right), 3.17\left(\mathrm{~s}, 3 \mathrm{H}, \mathrm{N}-\mathrm{CH}_{3}\right) ;{ }^{13} \mathrm{C} \mathrm{NMR}\left(100 \mathrm{MHz}, \mathrm{CDCl}_{3}\right) \delta 162.4,158.2,155.8,146.4,145.9$, 145.4, 145.2, 135.5, 131.4, 130.2, 129.3, 126.7, 119.2, 114.2, 114.0, 110.8, 56.0, 55.3, 32.2, 29.9, 28.8, 24.7; HRMS (ESI) calcd. for $\mathrm{C}_{24} \mathrm{H}_{26} \mathrm{~N}_{5} \mathrm{O}_{5}{ }^{+}[\mathrm{M}+\mathrm{H}]^{+} 464.1928$, found 464.1934.

For naamidine $\mathrm{H}$ (2c): Brown powder; Yield 81\%; m.p.: $144-146{ }^{\circ} \mathrm{C} ;{ }^{1} \mathrm{H}$ NMR $\left(400 \mathrm{MHz}, \mathrm{CDCl}_{3}\right) \delta 7.15$ $(\mathrm{d}, J=7.9 \mathrm{~Hz}, 2 \mathrm{H}, \mathrm{Ar}-\mathrm{H}), 6.80(\mathrm{~d}, J=7.9 \mathrm{~Hz}, 2 \mathrm{H}, \mathrm{Ar}-\mathrm{H}), 6.15(\mathrm{~s}, 2 \mathrm{H}, \mathrm{Ar}-\mathrm{H}), 3.91\left(\mathrm{~s}, 2 \mathrm{H}, \mathrm{CH}_{2}\right), 3.89(\mathrm{~s}, 2 \mathrm{H}$, $\left.\mathrm{CH}_{2}\right), 3.76\left(\mathrm{~s}, 3 \mathrm{H}, \mathrm{O}-\mathrm{CH}_{3}\right), 3.70\left(\mathrm{~s}, 6 \mathrm{H}, \mathrm{O}-\mathrm{CH}_{3}\right), 3.50\left(\mathrm{~s}, 3 \mathrm{H}, \mathrm{N}-\mathrm{CH}_{3}\right), 3.18\left(\mathrm{~s}, 3 \mathrm{H}, \mathrm{N}-\mathrm{CH}_{3}\right) ;{ }^{13} \mathrm{C}$ NMR $\left(100 \mathrm{MHz}, \mathrm{CDCl}_{3}\right) \delta 162.1,158.2,155.2,147.2,146.5,144.2,136.2,133.5,131.7,129.3,128.1,126.7,114.0$, 104.6, 56.2, 55.3, 32.2, 30.0, 29.7, 24.7; HRMS (ESI) calcd. for $\mathrm{C}_{25} \mathrm{H}_{28} \mathrm{~N}_{5} \mathrm{O}_{6}{ }^{+}[\mathrm{M}+\mathrm{H}]^{+} 494.2034$, found 494.2030.

For naamidine A (2d): Yellow powder; Yield 85\%; m.p.: $186-190{ }^{\circ} \mathrm{C} ;{ }^{1} \mathrm{H} \mathrm{NMR}\left(400 \mathrm{MHz}, \mathrm{CDCl}_{3}\right) \delta$ $7.11(\mathrm{~d}, J=8.5 \mathrm{~Hz}, 2 \mathrm{H}, \mathrm{Ar}-\mathrm{H}), 6.85-6.79(\mathrm{~m}, 4 \mathrm{H}, \mathrm{Ar}-\mathrm{H}), 6.74(\mathrm{~d}, J=8.4 \mathrm{~Hz}, 2 \mathrm{H}, \mathrm{Ar}-\mathrm{H}), 3.88\left(\mathrm{~s}, 2 \mathrm{H}, \mathrm{CH}_{2}\right)$, $3.87\left(\mathrm{~s}, 2 \mathrm{H}, \mathrm{CH}_{2}\right), 3.77\left(\mathrm{~s}, 3 \mathrm{H}, \mathrm{O}-\mathrm{CH}_{3}\right), 3.37\left(\mathrm{~s}, 3 \mathrm{H}, \mathrm{N}-\mathrm{CH}_{3}\right), 3.17\left(\mathrm{~s}, 3 \mathrm{H}, \mathrm{N}-\mathrm{CH}_{3}\right) ;{ }^{13} \mathrm{C} \mathrm{NMR}(100 \mathrm{MHz}$, $\left.\mathrm{CDCl}_{3}\right) \delta 163.5,158.3,157.7,155.2,148.5,146.4,133.7,130.9,129.3,129.0,128.1,126.8,115.8,114.1,55.3$, 31.7, 29.7, 28.6, 24.8; HRMS (ESI) calcd. for $\mathrm{C}_{23} \mathrm{H}_{24} \mathrm{~N}_{5} \mathrm{O}_{4}{ }^{+}[\mathrm{M}+\mathrm{H}]^{+} 434.1823$, found 434.1826.

General procedure for the preparation of naamines $1 \mathrm{e}-\mathbf{i}$. To the solution of $15 \mathrm{~d}(4.84 \mathrm{mmol})$ and $\mathrm{Et}_{3} \mathrm{~N}(9.68 \mathrm{mmol})$ in dichloromethane $(120 \mathrm{~mL})$ was added dropwise the solution of corresponding acyl chlorides $(9.68 \mathrm{mmol})$ in dichloromethane $(10 \mathrm{~mL})$, and stirred at room temperature for $20 \mathrm{~min}$. Then, con. $\mathrm{HCl}$ solution $(50 \mathrm{~mL})$ was added and stirred for further $20 \mathrm{~min}$. The layers were separated. The organic layer was washed with saturated $\mathrm{NaHCO}_{3}(100 \mathrm{~mL})$, dried over $\mathrm{MgSO}_{4}$ anhydrous, and evaporated to give 19. The solution of 19 and $\mathrm{Pd} / \mathrm{C}(10 \mathrm{wt} \%)(0.3 \mathrm{~g})$ in methanol $(100 \mathrm{~mL})$ was bubbled $\mathrm{H}_{2}$ and stirred at room temperature for $24 \mathrm{~h}$. The mixture was filtered and concentrated to give naamines 1e-i.

For 1e: White powder; Yield 92\% for three steps; m.p.: $161-163{ }^{\circ} \mathrm{C} ;{ }^{1} \mathrm{H} \mathrm{NMR}\left(400 \mathrm{MHz}, \mathrm{CDCl}_{3}\right) \delta 13.41$ $(\mathrm{s}, 1 \mathrm{H}), 11.03(\mathrm{~s}, 1 \mathrm{H}), 7.13(\mathrm{~d}, J=8.1 \mathrm{~Hz}, 2 \mathrm{H}, \mathrm{Ar}-\mathrm{H}), 6.85-6.77(\mathrm{~m}, 6 \mathrm{H}, \mathrm{Ar}-\mathrm{H}), 3.90\left(\mathrm{~s}, 2 \mathrm{H}, \mathrm{CH}_{2}\right), 3.86(\mathrm{~s}$, $\left.2 \mathrm{H}, \mathrm{CH}_{2}\right), 3.76\left(\mathrm{~s}, 3 \mathrm{H}, \mathrm{O}-\mathrm{CH}_{3}\right), 3.38\left(\mathrm{~s}, 3 \mathrm{H}, \mathrm{N}-\mathrm{CH}_{3}\right), 1.37\left(\mathrm{~s}, 9 \mathrm{H}, \mathrm{CCH}_{3}\right) ;{ }^{13} \mathrm{C}$ NMR (100 MHz, DMSO-d 6 ) 
$\delta 178.2,158.1,156.2,136.3,129.7,129.5,129.0,127.4,127.0,126.3,115.5,114.0,55.1,31.5,28.0,26.8,26.6$; HRMS (ESI) calcd. for $\mathrm{C}_{24} \mathrm{H}_{30} \mathrm{~N}_{3} \mathrm{O}_{3}{ }^{+}[\mathrm{M}+\mathrm{H}]^{+} 408.2282$, found 408.2282 .

For 1f: White powder; Yield $87 \%$ for three steps; m.p.: $162-164{ }^{\circ} \mathrm{C} ;{ }^{1} \mathrm{H}$ NMR $\left(400 \mathrm{MHz}, \mathrm{CDCl}_{3}\right) \delta 7.09$ $(\mathrm{d}, J=8.5 \mathrm{~Hz}, 2 \mathrm{H}, \mathrm{Ar}-\mathrm{H}), 6.85-6.77(\mathrm{~m}, 4 \mathrm{H}, \mathrm{Ar}-\mathrm{H}), 6.63(\mathrm{~d}, J=8.3 \mathrm{~Hz}, 2 \mathrm{H}, \mathrm{Ar}-\mathrm{H}), 3.85\left(\mathrm{~s}, 2 \mathrm{H}, \mathrm{CH}_{2}\right), 3.79$ $\left(\mathrm{s}, 2 \mathrm{H}, \mathrm{CH}_{2}\right), 3.76\left(\mathrm{~s}, 3 \mathrm{H}, \mathrm{O}-\mathrm{CH}_{3}\right), 3.13\left(\mathrm{~s}, 3 \mathrm{H}, \mathrm{N}-\mathrm{CH}_{3}\right), 2.39\left(\mathrm{t}, J=7.5 \mathrm{~Hz}, 2 \mathrm{H}, \mathrm{COCH}_{2}\right), 1.68-1.59(\mathrm{~m}$, $\left.2 \mathrm{H}, \mathrm{CH}_{2}\right), 1.30-1.25\left(\mathrm{~m}, 4 \mathrm{H}, \mathrm{CH}_{2} \mathrm{CH}_{2}\right), 0.84\left(\mathrm{t}, J=6.6 \mathrm{~Hz}, 3 \mathrm{H}, \mathrm{CH}_{3}\right) ;{ }^{13} \mathrm{C} \mathrm{NMR}\left(100 \mathrm{MHz}, \mathrm{CDCl}_{3}\right) \delta$ 158.3, 156.0, 130.5, 129.4, 128.7, 127.7, 123.1, 115.9, 114.1, 55.2, 37.7, 31.5, 30.8, 30.0, 28.2, 25.6, 22.5, 14.0; HRMS (ESI) calcd. for $\mathrm{C}_{25} \mathrm{H}_{32} \mathrm{~N}_{3} \mathrm{O}_{3}{ }^{+}[\mathrm{M}+\mathrm{H}]^{+} 422.2438$, found 422.2440 .

For 1g: White powder; Yield $68 \%$ for three steps; m.p.: $172-174{ }^{\circ} \mathrm{C} ;{ }^{1} \mathrm{H} \mathrm{NMR}\left(400 \mathrm{MHz}, \mathrm{CDCl}_{3}\right) \delta 9.57$ (s, 1H, NH), $7.84(\mathrm{~d}, J=7.3 \mathrm{~Hz}, 2 \mathrm{H}, \mathrm{Ar}-\mathrm{H}), 7.48-7.35(\mathrm{~m}, 3 \mathrm{H}, \mathrm{Ar}-\mathrm{H}), 7.03(\mathrm{~d}, J=8.6 \mathrm{~Hz}, 2 \mathrm{H}, \mathrm{Ar}-\mathrm{H}), 6.91$ $(\mathrm{d}, J=8.5 \mathrm{~Hz}, 2 \mathrm{H}, \mathrm{Ar}-\mathrm{H}), 6.85(\mathrm{~d}, J=8.6 \mathrm{~Hz}, 2 \mathrm{H}, \mathrm{Ar}-\mathrm{H}), 6.78(\mathrm{~d}, J=8.6 \mathrm{~Hz}, 2 \mathrm{H}, \mathrm{Ar}-\mathrm{H}), 3.81(\mathrm{~s}, 3 \mathrm{H}$, $\left.\mathrm{O}-\mathrm{CH}_{3}\right), 3.76\left(\mathrm{~s}, 4 \mathrm{H}, \mathrm{CH}_{2}\right), 3.07\left(\mathrm{~s}, 3 \mathrm{H}, \mathrm{N}-\mathrm{CH}_{3}\right) ;{ }^{13} \mathrm{C} \mathrm{NMR}\left(100 \mathrm{MHz}, \mathrm{DMSO}-d_{6}\right) \delta 157.7,156.0,145.2$, $144.8,131.3,130.9,129.1,128.9,128.5,127.3,125.5,121.5,121.4,115.3,113.7,55.0,28.7,27.8,27.0$; HRMS (ESI) calcd. for $\mathrm{C}_{25} \mathrm{H}_{26} \mathrm{~N}_{3} \mathrm{O}_{4} \mathrm{~S}^{+}[\mathrm{M}+\mathrm{H}]^{+} 464.1639$, found 464.1632 .

For 1h: White powder; Yield 57\% for three steps; m.p.: $207-209{ }^{\circ} \mathrm{C} ;{ }^{1} \mathrm{H}$ NMR (400 MHz, DMSO- $\left.d_{6}\right) \delta$ $12.16(\mathrm{~s}, 1 \mathrm{H}), 9.28(\mathrm{~s}, 1 \mathrm{H}), 8.09(\mathrm{~s}, 2 \mathrm{H}, \mathrm{Ar}-\mathrm{H}), 7.43(\mathrm{~s}, 3 \mathrm{H}, \mathrm{Ar}-\mathrm{H}), 7.20(\mathrm{~d}, J=7.6 \mathrm{~Hz}, 2 \mathrm{H}, \mathrm{Ar}-\mathrm{H}), 6.91(\mathrm{~d}$, $J=7.8 \mathrm{~Hz}, 2 \mathrm{H}, \mathrm{Ar}-\mathrm{H}), 6.85(\mathrm{~d}, J=7.7 \mathrm{~Hz}, 2 \mathrm{H}, \mathrm{Ar}-\mathrm{H}), 6.68(\mathrm{~d}, J=7.3 \mathrm{~Hz}, 2 \mathrm{H}, \mathrm{Ar}-\mathrm{H}), 3.93\left(\mathrm{~s}, 4 \mathrm{H}, \mathrm{CH}_{2}\right)$, $3.71\left(\mathrm{~s}, 3 \mathrm{H}, \mathrm{O}-\mathrm{CH}_{3}\right), 3.25\left(\mathrm{~s}, 3 \mathrm{H}, \mathrm{N}-\mathrm{CH}_{3}\right) ;{ }^{13} \mathrm{C} \mathrm{NMR}\left(100 \mathrm{MHz}, \mathrm{DMSO}-d_{6}\right) \delta 157.7,155.9,131.4,130.6$, 129.4, 129.0, 128.4, 128.2, 127.8, 127.6, 115.4, 113.8, 55.0, 28.9, 27.2; HRMS (ESI) calcd. for $\mathrm{C}_{26} \mathrm{H}_{26} \mathrm{~N}_{3} \mathrm{O}_{3}{ }^{+}$ $[\mathrm{M}+\mathrm{H}]^{+} 428.1969$, found 428.1971 .

For 1i: White powder; Yield 59\% for three steps; m.p.: 153-154 ${ }^{\circ} \mathrm{C} ;{ }^{1} \mathrm{H}$ NMR $\left(400 \mathrm{MHz}, \mathrm{CDCl}_{3}\right) \delta 10.47$ $(\mathrm{s}, 1 \mathrm{H}), 7.08(\mathrm{~d}, J=8.0 \mathrm{~Hz}, 2 \mathrm{H}, \mathrm{Ar}-\mathrm{H}), 6.91(\mathrm{~d}, J=7.9 \mathrm{~Hz}, 2 \mathrm{H}, \mathrm{Ar}-\mathrm{H}), 6.84(\mathrm{~d}, J=8.0 \mathrm{~Hz}, 2 \mathrm{H}, \mathrm{Ar}-\mathrm{H}), 6.80$ $(\mathrm{d}, J=7.9 \mathrm{~Hz}, 2 \mathrm{H}, \mathrm{Ar}-\mathrm{H}), 3.80\left(\mathrm{~s}, 4 \mathrm{H}, \mathrm{CH}_{2}\right), 3.79\left(\mathrm{~s}, 3 \mathrm{H}, \mathrm{O}-\mathrm{CH}_{3}\right), 3.15\left(\mathrm{~s}, 3 \mathrm{H}, \mathrm{N}-\mathrm{CH}_{3}\right), 3.02\left(\mathrm{~s}, 3 \mathrm{H}, \mathrm{S}-\mathrm{CH}_{3}\right)$; ${ }^{13} \mathrm{C}$ NMR $\left(100 \mathrm{MHz}, \mathrm{CDCl}_{3}\right) \delta 158.7,155.4,145.5,129.3,128.9,128.8,127.5,121.7,121.2,116.0,114.4$, 100.0, 55.4, 42.4, 29.3, 28.0; HRMS (ESI) calcd. for $\mathrm{C}_{20} \mathrm{H}_{24} \mathrm{~N}_{3} \mathrm{O}_{4} \mathrm{~S}^{+}[\mathrm{M}+\mathrm{H}]^{+} 402.1482$, found 402.1481 .

General procedure for the preparation of naamines $\mathbf{1 j}$ and $\mathbf{k}$. The solution of naamine A (1d, 3.00 mmol), benzaldehyde $(12.36 \mathrm{mmol})$ and acetic acid $(0.5 \mathrm{~mL})$ in ethanol $(120 \mathrm{~mL})$ was refluxed for $12 \mathrm{~h}$, evaporated part of ethanol, filtered to give 20. The mixture of 20 and $\mathrm{NaBH}_{4}(6.5 \mathrm{mmol})$ in ethanol $(100 \mathrm{~mL})$ was stirred at $65^{\circ} \mathrm{C}$ for $2 \mathrm{~h}$, quenched with $\mathrm{H}_{2} \mathrm{O}(10 \mathrm{~mL})$, and then concentrated. The residue was purified by column chromatography on silica gel to give naamines $\mathbf{1} \mathbf{j}$ and $\mathbf{1 k}$.

For 1j: White powder; Yield 16\%; m.p.: $226{ }^{\circ} \mathrm{C} ;{ }^{1} \mathrm{H}$ NMR (400 MHz, DMSO- $\left.d_{6}\right) \delta 9.18(\mathrm{~s}, 1 \mathrm{H}, \mathrm{OH}), 7.37$ $(\mathrm{d}, J=7.6 \mathrm{~Hz}, 2 \mathrm{H}, \mathrm{Ar}-\mathrm{H}), 7.33-7.19(\mathrm{~m}, 3 \mathrm{H}, \mathrm{Ar}-\mathrm{H}), 7.12(\mathrm{~d}, J=8.2 \mathrm{~Hz}, 2 \mathrm{H}, \mathrm{Ar}-\mathrm{H}), 6.84(\mathrm{~d}, J=7.9 \mathrm{~Hz}, 2 \mathrm{H}$, Ar-H), $6.77(\mathrm{~d}, J=8.2 \mathrm{~Hz}, 2 \mathrm{H}, \mathrm{Ar}-\mathrm{H}), 6.62(\mathrm{~d}, J=7.9 \mathrm{~Hz}, 2 \mathrm{H}, \mathrm{Ar}-\mathrm{H}), 5.88\left(\mathrm{t}, J=5.8 \mathrm{~Hz}, 1 \mathrm{H}, \mathrm{NHCH}_{2}\right)$, $4.32\left(\mathrm{~d}, J=5.8 \mathrm{~Hz}, 2 \mathrm{H}, \mathrm{NHCH}_{2}\right), 3.71\left(\mathrm{~s}, 2 \mathrm{H}, \mathrm{CH}_{2}\right), 3.69\left(\mathrm{~s}, 3 \mathrm{H}, \mathrm{O}-\mathrm{CH}_{3}\right), 3.63\left(\mathrm{~s}, 2 \mathrm{H}, \mathrm{CH}_{2}\right), 3.03(\mathrm{~s}, 3 \mathrm{H}$, $\left.\mathrm{N}-\mathrm{CH}_{3}\right) ;{ }^{13} \mathrm{C}$ NMR $\left(101 \mathrm{MHz}\right.$, DMSO- $\left.d_{6}\right) \delta 157.1,155.5,148.8,140.7,133.8,131.5,129.7,129.3,128.8$, 128.0, 127.7, 126.5, 120.6, 115.1, 113.3, 54.9, 46.5, 31.9, 28.6, 27.8; HRMS (ESI) calcd. for $\mathrm{C}_{26} \mathrm{H}_{28} \mathrm{~N}_{3} \mathrm{O}_{2}{ }^{+}$ $[\mathrm{M}+\mathrm{H}]^{+} 414.2176$, found 414.2167 .

For 1k: White powder; Yield 16\%; m.p.: $226-228^{\circ} \mathrm{C} ;{ }^{1} \mathrm{H}$ NMR $\left(400 \mathrm{MHz}\right.$, DMSO- $\left.d_{6}\right) \delta 9.20(\mathrm{~s}, 1 \mathrm{H}), 7.12$ $(\mathrm{d}, J=7.9 \mathrm{~Hz}, 2 \mathrm{H}, \mathrm{Ar}-\mathrm{H}), 6.83(\mathrm{~d}, J=7.8 \mathrm{~Hz}, 2 \mathrm{H}, \mathrm{Ar}-\mathrm{H}), 6.77(\mathrm{~d}, J=7.9 \mathrm{~Hz}, 2 \mathrm{H}, \mathrm{Ar}-\mathrm{H}), 6.61(\mathrm{~d}, J=7.8$ $\mathrm{Hz}, 2 \mathrm{H}, \mathrm{Ar}-\mathrm{H}), 5.02(\mathrm{t}, J=6.1 \mathrm{~Hz}, 1 \mathrm{H}, \mathrm{NH}), 3.69\left(\mathrm{~s}, 5 \mathrm{H}, \mathrm{O}-\mathrm{CH}_{3}\right.$ and $\left.\mathrm{CH}_{2}\right), 3.62\left(\mathrm{~s}, 2 \mathrm{H}, \mathrm{CH}_{2}\right), 3.02(\mathrm{~s}$, $\left.3 \mathrm{H}, \mathrm{N}-\mathrm{CH}_{3}\right), 2.96\left(\mathrm{~d}, J=6.1 \mathrm{~Hz}, 2 \mathrm{H}, \mathrm{NHCH}_{2}\right), 0.88\left(\mathrm{~s}, 9 \mathrm{H}, \mathrm{CCH}_{3}\right) ;{ }^{13} \mathrm{C}$ NMR $\left(100 \mathrm{MHz}, \mathrm{DMSO}-d_{6}\right) \delta$ 157.1, 155.4, 149.5, 133.8, 131.2, 129.8, 129.2, 128.8, 120.4, 115.0, 113.3, 54.9, 54.3, 31.8, 31.8, 28.6, 27.8, 27.4; HRMS (ESI) calcd. for $\mathrm{C}_{24} \mathrm{H}_{32} \mathrm{~N}_{3} \mathrm{O}_{2}{ }^{+}[\mathrm{M}+\mathrm{H}]^{+} 394.2489$, found 394.2483.

Synthesis of 4,5-bis(4-methoxybenzyl)-1,3-dimethyl-1H-imidazol-2(3H)-one (11). To the solution of $1 \mathbf{d}(0.50 \mathrm{~g}, 1.54 \mathrm{mmol})$ in THF $(100 \mathrm{~mL})$ was added $70 \% \mathrm{NaH}(12.36 \mathrm{mmol})$ and methyliodide $(12.36$ mmol) successively at $0{ }^{\circ} \mathrm{C}$ under argon. Then the mixture was stirred at $70{ }^{\circ} \mathrm{C}$ for $24 \mathrm{~h}$, quenched with $\mathrm{H}_{2} \mathrm{O}(10 \mathrm{~mL})$, concentrated, acidified to $\mathrm{pH} 4-5$ with dilute hydrochloric acid and extracted 
with dichloromethane. The combined organic layer was washed successively with saturated aqueous $\mathrm{NaHCO}_{3}$ solution $(100 \mathrm{~mL}), \mathrm{H}_{2} \mathrm{O}(100 \mathrm{~mL})$, and brine $(100 \mathrm{~mL})$, then dried over $\mathrm{MgSO}_{4}$ anhydrous, filtered and concentrated. The residue was purified by column chromatography on silica gel to give 11 $(0.37 \mathrm{~g}, 68 \%)$ as a white powder. m.p.: $157-159{ }^{\circ} \mathrm{C} ;{ }^{1} \mathrm{H}$ NMR $\left(400 \mathrm{MHz}\right.$, DMSO- $\left.d_{6}\right) \delta 7.08(\mathrm{~d}, J=8.6 \mathrm{~Hz}$, $4 \mathrm{H}, \mathrm{Ar}-\mathrm{H}), 6.86(\mathrm{~d}, J=8.6 \mathrm{~Hz}, 4 \mathrm{H}, \mathrm{Ar}-\mathrm{H}), 3.84\left(\mathrm{~s}, 4 \mathrm{H}, \mathrm{CH}_{2}\right), 3.72\left(\mathrm{~s}, 6 \mathrm{H}, \mathrm{O}-\mathrm{CH}_{3}\right), 2.89\left(\mathrm{~s}, 6 \mathrm{H}, \mathrm{N}-\mathrm{CH}_{3}\right)$; ${ }^{13} \mathrm{C} \mathrm{NMR}\left(100 \mathrm{MHz}, \mathrm{CDCl}_{3}\right) \delta 158.4,153.8,129.9,128.8,117.5,114.1,55.3,28.3,27.8$; HRMS (ESI) calcd. for $\mathrm{C}_{21} \mathrm{H}_{25} \mathrm{~N}_{2} \mathrm{O}_{3}{ }^{+}[\mathrm{M}+\mathrm{H}]^{+}$353.1860, found 353.1879.

General procedure for the preparation of naamines $\mathbf{1 m}-\mathbf{o}$. The solution of $\mathbf{1 d}(0.35 \mathrm{~g}, 1.08 \mathrm{mmol})$ and corresponding acids $(2.16 \mathrm{mmol})$ in methanol $(100 \mathrm{~mL})$ was stirred at $50{ }^{\circ} \mathrm{C}$ for $2 \mathrm{~h}$ and concentrated. Then, acetone $(5 \mathrm{~mL})$ and petroleum ether $(5 \mathrm{~mL})$ were added, filtered to give $\mathbf{1} \mathbf{m}-\mathbf{o}$.

For 1m: White powder; Yield 98\%; m.p.: $45-47{ }^{\circ} \mathrm{C} ;{ }^{1} \mathrm{H}$ NMR (400 MHz, DMSO) $\delta 12.14(\mathrm{~s}, 1 \mathrm{H}, \mathrm{OH})$, $9.37(\mathrm{~s}, 1 \mathrm{H}, \mathrm{NH}), 7.47\left(\mathrm{~s}, 2 \mathrm{H}, \mathrm{NH}_{2}\right), 7.15(\mathrm{~d}, J=8.7 \mathrm{~Hz}, 2 \mathrm{H}, \mathrm{Ar}-\mathrm{H}), 6.91(\mathrm{~d}, J=8.5 \mathrm{~Hz}, 2 \mathrm{H}, \mathrm{Ar}-\mathrm{H}), 6.86$ $(\mathrm{d}, J=8.7 \mathrm{~Hz}, 2 \mathrm{H}, \mathrm{Ar}-\mathrm{H}), 6.69(\mathrm{~d}, J=8.5 \mathrm{~Hz}, 2 \mathrm{H}, \mathrm{Ar}-\mathrm{H}), 3.86\left(\mathrm{~s}, 2 \mathrm{H}, \mathrm{CH}_{2}\right), 3.81\left(\mathrm{~s}, 2 \mathrm{H}, \mathrm{CH}_{2}\right), 3.72(\mathrm{~s}$, $\left.3 \mathrm{H}, \mathrm{O}-\mathrm{CH}_{3}\right), 3.15\left(\mathrm{~s}, 3 \mathrm{H}, \mathrm{N}-\mathrm{CH}_{3}\right) ;{ }^{13} \mathrm{C}$ NMR $(101 \mathrm{MHz}$, DMSO) $\delta 157.9,156.1,146.1,130.2,129.4,128.9$, 127.1, 122.2, 121.7, 115.4, 113.9, 55.1, 29.5, 27.9, 26.6 .

For 1n: White powder; Yield 98\%; m.p.: $123-125{ }^{\circ} \mathrm{C} ;{ }^{1} \mathrm{H}$ NMR (400 MHz, DMSO) $\delta 12.21$ (s, $\left.1 \mathrm{H}, \mathrm{OH}\right)$, $9.36(\mathrm{~s}, 1 \mathrm{H}, \mathrm{NH}), 7.47\left(\mathrm{~s}, 2 \mathrm{H}, \mathrm{NH}_{2}\right), 7.14(\mathrm{~d}, J=8.5 \mathrm{~Hz}, 2 \mathrm{H}, \mathrm{Ar}-\mathrm{H}), 6.92(\mathrm{~d}, J=8.3 \mathrm{~Hz}, 2 \mathrm{H}, \mathrm{Ar}-\mathrm{H}), 6.86(\mathrm{~d}$, $J=8.5 \mathrm{~Hz}, 2 \mathrm{H}, \mathrm{Ar}-\mathrm{H}), 6.68(\mathrm{~d}, J=8.3 \mathrm{~Hz}, 2 \mathrm{H}, \mathrm{Ar}-\mathrm{H}), 3.87\left(\mathrm{~s}, 2 \mathrm{H}, \mathrm{CH}_{2}\right), 3.81\left(\mathrm{~s}, 2 \mathrm{H}, \mathrm{CH}_{2}\right), 3.72(\mathrm{~s}, 3 \mathrm{H}$, $\left.\mathrm{O}-\mathrm{CH}_{3}\right), 3.15\left(\mathrm{~s}, 3 \mathrm{H}, \mathrm{N}-\mathrm{CH}_{3}\right) ;{ }^{13} \mathrm{C}$ NMR $(100 \mathrm{MHz}, \mathrm{DMSO}) \delta 158.8(\mathrm{q}, J=32.7 \mathrm{~Hz}), 158.0,156.1,146.2$, $130.1,129.3,129.0,127.1,122.2,121.7,118.2,115.4,113.9,55.0,29.3,28.0,26.6$.

For 1o: White powder; Yield 58\%; m.p.: $172-174{ }^{\circ} \mathrm{C} ;{ }^{1} \mathrm{H}$ NMR $(400 \mathrm{MHz}, \mathrm{DMSO}) \delta 7.94(\mathrm{~d}, J=7.4 \mathrm{~Hz}$, 2H, Ar-H), 7.54-7.40 (m, 3H, Ar-H), 7.20 (d, J = 8.3 Hz, 2H, Ar-H), 6.95-6.84 (m, 4H, Ar-H and $\mathrm{NH}_{2}$ ), $6.80(\mathrm{~d}, J=8.3 \mathrm{~Hz}, 2 \mathrm{H}, \mathrm{Ar}-\mathrm{H}), 6.66(\mathrm{~d}, J=8.2 \mathrm{~Hz}, 2 \mathrm{H}, \mathrm{Ar}-\mathrm{H}), 3.81\left(\mathrm{~s}, 2 \mathrm{H}, \mathrm{CH}_{2}\right), 3.70\left(\mathrm{~s}, 2 \mathrm{H}, \mathrm{CH}_{2}\right), 3.69(\mathrm{~s}$, $\left.3 \mathrm{H}, \mathrm{O}-\mathrm{CH}_{3}\right), 3.06\left(\mathrm{~s}, 3 \mathrm{H}, \mathrm{N}-\mathrm{CH}_{3}\right) ;{ }^{13} \mathrm{C}$ NMR $(100 \mathrm{MHz}, \mathrm{DMSO}) \delta 170.5,158.1,156.3,148.3,132.0,131.4$, 130.0, 129.6, 129.4, 128.7, 128.4, 121.1, 115.8, 114.1, 55.5, 30.0, 29.4, 27.5.

Synthesis of naamidine-metal complex 2e. The mixture of $2 \mathrm{~d}(0.50 \mathrm{~g}, 1.15 \mathrm{mmol}), \mathrm{ZnSO}_{4} \cdot 7 \mathrm{H}_{2} \mathrm{O}$ $(69 \mathrm{mmol})$ in $\mathrm{H}_{2} \mathrm{O}(200 \mathrm{~mL})$ and dichloromethane $(100 \mathrm{~mL})$ was stirred at room temperature for $3 \mathrm{~h}$, filtered to give 2e. Yellow powder; Yield 38\%; m.p.: $185-187^{\circ} \mathrm{C} ;{ }^{1} \mathrm{H}$ NMR $\left(400 \mathrm{MHz}\right.$, DMSO- $\left.d_{6}\right) \delta 9.30$ $(\mathrm{s}, 2 \mathrm{H}, \mathrm{OH}), 6.95(\mathrm{~d}, J=8.2 \mathrm{~Hz}, 4 \mathrm{H}, \mathrm{Ar}-\mathrm{H}), 6.69(\mathrm{~d}, J=8.2 \mathrm{~Hz}, 4 \mathrm{H}, \mathrm{Ar}-\mathrm{H}), 6.50(\mathrm{~s}, 8 \mathrm{H}, \mathrm{Ar}-\mathrm{H}), 4.04-3.90$ $\left(\mathrm{m}, 4 \mathrm{H}, \mathrm{CH}_{2}\right), 3.82\left(\mathrm{~d}, J=16.7 \mathrm{~Hz}, 2 \mathrm{H}, \mathrm{CH}_{2}\right), 3.62\left(\mathrm{~s}, 6 \mathrm{H}, \mathrm{O}-\mathrm{CH}_{3}\right), 3.57\left(\mathrm{~s}, 6 \mathrm{H}, \mathrm{N}-\mathrm{CH}_{3}\right), 3.26(\mathrm{~d}, J=16.7$ $\left.\mathrm{Hz}, 2 \mathrm{H}, \mathrm{CH}_{2}\right), 2.80$ (s, 6H, N-CH 3$) ;{ }^{13} \mathrm{C}$ NMR (100 MHz, DMSO- $\left.d_{6}\right) \delta 163.7,160.5,157.3,155.9,153.2$, 146.8, 132.0, 129.9, 129.0, 128.4, 128.3, 127.7, 115.4, 113.0, 54.7, 30.2, 29.9, 27.4, 24.0; HRMS (ESI) calcd. for $\mathrm{C}_{46} \mathrm{H}_{45} \mathrm{~N}_{10} \mathrm{O}_{8} \mathrm{Zn}^{+}[\mathrm{M}+\mathrm{H}]^{+}$929.2708, found 929.2709.

\subsection{Biological Assay}

Each bioassay was repeated three times at $25 \pm 1{ }^{\circ} \mathrm{C}$. Activity results were estimated according to a percentage scale of 0-100 (0: no activity; 100: total kill).

Detailed bioassay procedures for the anti-TMV [15] and fungicidal [24] activity were described in our published literature.

\section{Conclusions}

Marine natural products naamines A, F and G, naamidines A, B and $\mathrm{H}$, and various derivatives were synthesized, and their activities against a plant virus and phytopathogenic fungi were evaluated for the first time. The introduction of a benzyl group on the aromatic ring was favorable for activity. Derivative 15d, which had higher antiviral activity than ribavirin in all the assays, emerged as a new lead compound for antiviral research. Salification and derivatization of amino-group attenuated activity. Assays on 14 kinds of phytopathogenic fungi revealed that these compounds displayed very good fungicidal activity at $50 \mathrm{\mu g} / \mathrm{mL}$. Again, 15d emerged as a new lead compound for fungicidal 
research, owing to its broad-spectrum fungicidal activity. We expect that the results of our study will provide a basis for the development of these alkaloids as antiviral and fungicidal agents.

Supplementary Materials: The following are available online at http://www.mdpi.com/1660-3397/16/9/311/s1, ${ }^{1} \mathrm{H}$ and ${ }^{13} \mathrm{C}$ NMR, HRMS spectra of compounds $\mathbf{1}, \mathbf{2}$ and 15.

Author Contributions: Conceptualization, Z.W. and Q.W.; Methodology, Z.W.; Software, Z.W.; Validation, P.G., Z.W. and Q.W.; Formal Analysis, G.L.; Investigation, Y.L.; Resources, A.L.; Data Curation, A.L.; Writing-Original Draft Preparation, P.G.; Writing-Review \& Editing, Z.W.; Visualization, Z.W.; Supervision, Q.W.; Project Administration, Z.W.; Funding Acquisition, Q.W.

Funding: This research was funded by the National Natural Science Foundation of China $(21772145,21732002$, 21672117), Tianjin Natural Science Foundation (16JCZDJC32400).

Conflicts of Interest: The authors declare no conflict of interest. The funders had no role in the design of the study; in the collection, analyses, or interpretation of data; in the writing of the manuscript, and in the decision to publish the results.

\section{References}

1. Godfrey, H.C.J; Beddington, J.R.; Crute, I.R.; Haddad, L.; Lawrence, D.; Muir, J.F.; Pretty, J.; Robinson, S.; Thomas, S.M.; Toulmin, C. Food security: The challenge of feeding 9 billion people. Science 2010, 327, 812-818. [CrossRef] [PubMed]

2. Ray, D.K.; Mueller, N.D.; West, P.C.; Foley, J.A. Yield trends are insufficient to double global crop production by 2050. PLoS ONE 2013, 8, e66428. [CrossRef] [PubMed]

3. Liu, L.R. The Control of Disease and Pests of Tobacco; Science Press: Beijing, China, 1998; p. 31.

4. Song, B.A.; Yang, S.; Jin, L.H.; Bhadury, P.S. Environment-Friendly Anti-Plant Viral Agents; Springer Chemical Industry Press: Beijing, China, 2009; pp. 1-305.

5. Cheer, C.J.; Pickles, F.J. The crystal and molecular structure of 1,3-bis (thiocarbamoyl)-2-NN-dimethylaminopropane hydrochloride (Cartap). J. Chem. Soc. Perkin Trans. 2 1980, 12, 1805-1808. [CrossRef]

6. Kumar, A.S.P.; Amalnath, D.; Dutta, T.K. Cartap poisoning: A rare case report. Indian J. Crit. Care Med. 2011, 15, 233-235. [CrossRef] [PubMed]

7. Molinski, T.F.; Dalisay, D.S.; Lievens, S.L.; Saludes, J.P. Drug development from marine natural products. Nat. Rev. Drug. Discov. 2009, 8, 69-85. [CrossRef] [PubMed]

8. Carmely, S.; Kashman, Y. Naamines and Naamidines, novel imidazole alkaloids from the calcareous sponge Leucetta chagosensis. Tetrahedron Lett. 1987, 28, 3003-3006. [CrossRef]

9. Carmely, S.; Ilan, M.; Kashman, Y. 2-Amino imidazole alkaloids from the marine sponge Leucetta chagosensis. Tetrahedron 1989, 45, 2193-2200. [CrossRef]

10. Gross, H.; Kehraus, S.; König, G.M.; Woerheide, G.; Wright, A.D. New and biologically active imidazole alkaloids from two sponges of the genus Leucetta. J. Nat. Prod. 2002, 65, 1190-1193. [CrossRef] [PubMed]

11. Plubrukarn, A.; Smith, D.; Cramer, R.; Davidson, B. (2E,9E)-Pyronaamidine 9-(N-methylimine), a new imidazole alkaloid from the Northern Mariana Islands Sponge Leucetta sp. cf. Chagosensis. J. Nat. Prod. 1997, 60, 712-715. [CrossRef] [PubMed]

12. Akee, R.K.; Carroll, T.R.; Yoshida, W.Y.; Scheuer, P.J.; Stout, T.J.; Clardy, J. Two imidazole alkaloids from a sponge. J. Org. Chem. 1990, 55, 1944-1946. [CrossRef]

13. Crews, P.; Clark, D.; Tenney, K. Variation in the alkaloids among Indo-Pacific Leucetta Sponges. J. Nat. Prod. 2003, 66, 177-182. [CrossRef] [PubMed]

14. James, R.D.; Jones, D.A.; Aalbersberg, W.; Ireland, C.M. Naamidine A intensifies the phosphotransferase activity of extracellular signal-regulated kinases causing A-431 cells to arrest in G1. Mol. Cancer Ther. 2003, 2, 747-751. [PubMed]

15. Wang, Z.W.; Wei, P.; Wang, L.Z.; Wang, Q.M. Design, synthesis, and anti-tobacco mosaic virus (TMV) activity of phenanthroindolizidines and their analogues. J. Agric. Food Chem. 2012, 60, 10212-10219. [CrossRef] [PubMed]

16. Song, H.J.; Liu, Y.X.; Liu, Y.X.; Wang, L.Z.; Wang, Q.M. Synthesis and antiviral and fungicidal activity evaluation of $\beta$-carboline, dihydro- $\beta$-carboline, tetrahydro- $\beta$-carboline alkaloids, and their derivatives. J. Agric. Food Chem. 2014, 62, 1010-1018. [CrossRef] [PubMed] 
17. Ji, X.F.; Wang, Z.W.; Dong, J.; Liu, Y.X.; Lu, A.D.; Wang, Q.M. Discovery of Topsentin alkaloids and their derivatives as novel antiviral and anti-phytopathogenic fungus agents. J. Agric. Food Chem. 2016, 64, 9143-9151. [CrossRef] [PubMed]

18. Ni, W.J.; Li, C.J.; Liu, Y.X.; Song, H.J.; Wang, L.Z.; Song, H.B.; Wang, Q.M. Various bioactivity and relationship of structure-activity of matrine analogues. J. Agric. Food Chem. 2017, 65, 2039-2047. [CrossRef] [PubMed]

19. Ohta, S.; Tsuno, N.; Nakamura, S. Total syntheses of naamine A and naamidine A, marine imidazole alkaloids. Heterocycles 2000, 53, 1939-1955. [CrossRef]

20. Kawasaki, I.; Nakamura, S.; Yanagitani, S.; Kakuno, A.; Yamashita, M.; Ohta, S. New access to 1,3-dialkyl-2,3-dihydro-2-imino- $1 H$-imidazoles and their application to the first total synthesis of naamine B, a marine 2,3-dihydro-2-imino-1,3-dimethyl-1H-imidazole alkaloid. J. Chem. Soc. Perkin Trans. 1 2001, 23, 3095-3099. [CrossRef]

21. Ermolat'ev, D.S.; Bariwal, J.B.; Steenackers, H.P.; De Keersmaecker, S.C.; Van der Eycken, E.V. Concise and diversity-oriented route toward polysubstituted 2-aminoimidazole alkaloids and their analogues. Angew. Chem. Int. Ed. 2010, 49, 9465-9468. [CrossRef] [PubMed]

22. Koswatta, P.B.; Lovely, C.J. Total syntheses of naamidine G and 14-methoxynaamidine G. Tetrahedron Lett. 2010, 51, 164-166. [CrossRef] [PubMed]

23. Koswatta, P.B.; Lovely, C.J. Concise total synthesis of naamine G and naamidine H. Chem. Commun. 2010, 46, 2148-2150. [CrossRef] [PubMed]

24. Zhao, H.P.; Liu, Y.X.; Cui, Z.P.; Beattie, D.; Gu, Y.C.; Wang, Q.M. Design, synthesis, and biological activities of arylmethylamine substituted chlorotriazine and methylthiotriazine compounds. J. Agric. Food Chem. 2011, 59, 11711-11717. [CrossRef] [PubMed]

(C) 2018 by the authors. Licensee MDPI, Basel, Switzerland. This article is an open access article distributed under the terms and conditions of the Creative Commons Attribution (CC BY) license (http:/ / creativecommons.org/licenses/by/4.0/). 